\title{
Escuelas: espacios equivocados frente a los deseados por escolares
}

Schools: wrong spaces face the ones desired by the students

\section{Volumen 17, Número 3}

Setiembre-Diciembre

pp. 1-33

Este número se publica el $1^{\circ}$ de setiembre de 2017

DOI: http://dx.doi.org/10.15517/aie.v17i3.29824

Amparo Alonso-Sanz

Revista indizada en REDALYC, SCIELO

Revista distribuida en las bases de datos:

LATINDEX, DOAJ, REDIB, IRESIE, CLASE, DIALNET, SHERPA/ROMEO, QUALIS-CAPES, MIAR

Revista registrada en los directorios:

ULRICH'S, REDIE, RINACE, OEEI, MAESTROTECA, PREAL, $\underline{\text { CLACSO }}$ 


\title{
Escuelas: espacios equivocados frente a los deseados por escolares

\author{
Schools: wrong spaces face the ones desired by the students
}

\begin{abstract}
Amparo Alonso-Sanz ${ }^{1}$
Resumen: Este trabajo estudia las ideas que algunos estudiantes tienen sobre la mejora de su espacio, es decir, las proyecciones de los deseos de escolares hacia su propio centro educativo. Este estudio sobre la calidad estética se desarrolla gracias a la participación de tres colegios de Educación Infantil y Educación Primaria de Alicante, en España. La metodología es mixta pues combina la investigación educativa basada en las Artes Visuales y la investigación basada en imágenes para obtener mediante métodos gráficos la voz visual infantil. Los productos son diversos dibujos y collages que expresan información y contenido comunicativo analizado de manera cualitativa y cuantitativa. Con base en estos productos se concluye con la estética de los entornos educativos deseados. Esta estética queda definida como espacios frescos; naturales; concebidos tanto para la actividad lúdica o el aprendizaje como para el descanso y las relaciones interpersonales afectivas; atractivos, acogedores, cómodos y hogareños; permeables al entorno exterior rural o urbano; y con apariencia externa original. Se comprueba que las demandas colegiales no siempre coinciden con las respuestas otorgadas por adultos. Lo anterior, apunta a la urgencia de escuchar la voz de todos los colectivos implicados en los procesos de enseñanza y de aprendizaje.
\end{abstract}

Palabras clave: estética, edificios educacionales, estudiantes, creación artística

Abstract: This work examines the ideas that some students have about improving their space, projections of desires that children have toward their own school. This study about the aesthetic quality it's developed thanks to the participation of three primary schools in Alicante city, Spain. The methodology combines Visual Arts Based Educational Research and Image Based Research to obtain by graphical methods the visual voice of children. The results are different drawings and collages rich in information and in communication contents, which are analysed qualitatively and quantitatively. We conclude with the aesthetics of the desired educational environments. The space is defined as fresh and natural; designed for both recreational activity and learning, as for rest and affective interpersonal relationships; attractive, cozy, comfortable and homely; permeable to the outside rural or urban environment; and with a creative external appearance. It is found that the demands of students do not always coincide with the answers given by adults. We point the urgent need of hearing the voice of all those involved in the process of teaching and learning.

Key words: aesthetic, educational buildings, students, artistic creation

1 Universidad de Valencia, España. Profesora de Educación Artística en el área de Expresión Plástica del Departamento de Didáctica de la Expresión Musical, Plástica y Corporal.

Dirección electrónica: M.Amparo.Alonso@uv.es

Artículo recibido: 11 de octubre, 2016

Enviado a corrección: 27 de abril, 2017

Aprobado: 15 de mayo, 2017 


\section{Introducción}

El concepto espacio es un término polisémico. En el ámbito educativo nos permite entender las infraestructuras materiales (aulas, despachos, patios...) y las vivencias, emociones y relaciones de poder que se establecen dentro del sistema escolar. Es decir, los espacios dejan de ser unos simples recipientes para pasar a convertirse, mediante la apropiación y uso que de ellos hacen los individuos y los colectivos, en espacios sentidos, espacios vividos. De esta manera un concepto abstracto se convierte en concreto, personal y social para los individuos y grupos; esto mismo significa que para la arquitectura escolar el espacio construido es un lugar vital. Un espacio público con normas creadas para disciplinar a las personas. (Campo, Císcar y Souto, 2014, p. 01)

La arquitectura escolar define las condiciones de confort en las que van a desarrollarse los procesos de enseñanza aprendizaje. Y también ocurre a la inversa, existe "una relación entre el desarrollo infantil, la práctica educativa, y las implicaciones de estos factores en el diseño"2 (Burke, Gallagher, Prosser y Torrington, 2006, p. 1). Pedagogía y espacio se conciben como una unidad a la hora de diseñar (Fisher, 2005). Todo proyecto, por prescripción legislativa, va a velar por los condicionantes estructurales, higiénico sanitarios, térmicos, acústicos, relativos a instalaciones eléctricas, de iluminación, de saneamiento, agua potable, telecomunicaciones, de seguridad frente al fuego, rayo o sismo. Pero también puede atender las necesidades de zonas verdes, gestión de residuos, relación con el entorno circundante. Asimismo, va a determinar los acabados constructivos exteriores e interiores, la calidad de los materiales empleados, su durabilidad y el mantenimiento futuro del conjunto. Todo ello mediante el estudio y diseño tanto exterior como interior, donde tiene cabida incluso el mobiliario.

No cabe duda de que el propio edificio se erige como continente estético capaz de albergar subestructuras estéticas a su vez. Y que esta envolvente puede dotar de un sentido y significado simbólico a cuanto recoja en su interior. Las formas, volúmenes, colores, composiciones, huecos... van a formar parte de ese lenguaje generador de experiencias estéticas en la escuela.

\footnotetext{
2 "relationship between the developing child, educational practise, and the implications of these factors on design"
} (Burke, Gallagher, Prosser y Torrington, 2006, p. 1). 
La estética cotidiana es un concepto relacionado con la experiencia estética en el día a día, fuera de los entornos culturales tales como museos o galerías de arte donde tradicionalmente tenían cabida, más allá de las artes y la filosofía. La experiencia estética cotidiana ubicada en los tránsitos al trabajo, en los viajes, en lo recreativo, en lo ordinario, aun cuando puedan parecer triviales, pueden tener grandes consecuencias en la calidad de vida. Centramos nuestro interés en la experiencia estética cotidiana (Light y Smith, 2005; Mandoki, 1994, 2006; Saito, 2007) que se produce en escolares en la relación con su entorno educativo. La estética cotidiana escolar puede ser valorada en relación con la experimentación de valores como el orden, la belleza, la limpieza o sus opuestos, muy vinculados a lo visual. Pero también respecto al bienestar, la versatilidad, la libertad o contrarios como la incomodidad, la inmovilidad y la restricción, más asociados a lo corporal. Y esta experiencia se produce en actos recreativos y ordinarios. Según Errázuriz-Larraín (2015) la estética cotidiana escolar se caracteriza porque: [1] permite defender perspectivas estético-visuales que guarden coherencia con los proyectos educativos desarrollados en las escuelas; [2] es complejo generar espacios educativos estéticamente consistentes que comuniquen, a través del entorno, los valores que deseamos que experimenten los niños y las niñas en su interior; [3] el fenómeno estético es cotidiano, relativo a las rutinas diarias y no tiene que ver solamente con lo extraordinario; [4] desde la perspectiva prosaica de Mandoki, centra la atención en la experiencia estética del sujeto en relación con su entorno.

\section{Breve referente teórico}

El presente texto muestra parte de los resultados del proyecto de investigación "Estudio de la calidad estética de tres centros educativos valencianos"3. En el mencionado estudio, cobra un especial interés la opinión del colectivo escolar, su derecho a ser activos en modelar sus identidades sociales y el reconocimiento como membresía competente de una sociedad que debe escuchar sus voces (Burke y Grosvenor, 2003). La calidad estética escolar no es reducible a los edificios (Flores, 2015), contemplamos en el proyecto, por tanto, todo el entorno institucional, las imágenes que contiene y variables de conducta interna, aunque el presente trabajo se centra especialmente en la funcionalidad y distribución del espacio como aspecto arquitectónico imbricado en ella. La calidad estética escolar se logra con la mejora del entorno arquitectónico, con el enriquecimiento de la cultura visual presente

3 UV-INV-AE15_332576 de la Convocatoria de Ayudas para Acciones Especiales de Investigación 2015 del Vicerrectorado de Investigación y Política Científica de la Universidad de Valencia. 
en su interior y con las experiencias sensoriales que genere en quien habita los centros. Además, referirnos en términos de calidad implica, también, cuestiones éticas como la consideración de los intereses no solo de las personas adultas, sino también del menor.

La voz infantil ha sido uno de los retos de muchos investigadores que han logrado aproximarse a ella a través de métodos de investigación visuales (Alschuler y Hattwick, 1947; Burke, 2007; Burke, Gallagher, Prosser y Torrington, 2006; Burke y Grosvenor, 2003: Clark, 2010; Lipponen, Rajala, Hilppö y Paananen, 2015). Entre estos métodos el dibujo y la fotografía son los más destacados; es por ello que consideramos las advertencias de Ives y Gardner (1984) sobre el dibujo infantil. Dichos autores consideran que el apogeo de las influencias culturales se produce entre los 7 y los 12 años; es decir, un periodo en el que el menor va a ser más capaz de contextualizar sus necesidades. En esta misma línea, las contribuciones de Montessori, y con mayor claridad, de Steiner y la pedagogía Waldorf sobre la diferencia sustancial entre los 3 primeros septenios de edad y las necesidades intrínsecas de cada uno de estos períodos, en términos de educación, nos hacen reconocer las limitaciones que supone desarrollar un estudio con igual tratamiento y objeto para estudiantes de diferentes edades, que englobaría tanto a estudiantes del primer septenio (3 a 7 años) como a estudiantes del segundo (8 a 10 años). En relación con los septenios de vida, según Steiner, y a la arquitectura, afirma Araneda (2010):

Durante el primero somos seres esencialmente volitivos y por lo tanto prevalece en nosotros la actividad del sistema metabólico. Desde un punto de vista alegórico arquitectónico, arquitectura de corte puramente funcional bastaría para acoger a un ser de este nivel de complejidad, puesto que, aparte de la omnipresencia materna, a estas alturas no necesitamos más que es un espacio poblado con los colores y juguetes adecuados y, por sobre todo, una superficie limpia, suave y cálida sobre la cual deslizarnos. En jerga vanderliana, diríamos que nuestra demanda primordial durante el primer septenio es por un espacio capaz de acoger en plenitud nuestra experiencia elemental.

El segundo septenio se caracteriza por la construcción de un mundo anímico habitado fundamentalmente por simpatías y antipatías. Pasamos así de ser seres volitivos a ser además seres intrínsecamente emotivos. Para acoger a un ser de este nivel de complejidad, el obrar arquitectural debe encumbrarse por sobre aspectos puramente fisiológicos, pues ya existe el riesgo de que nuestro incipiente -si bien inconsciente juicio estético determine que un objeto arquitectónico nos repela 
visualmente; utilizando una expresión infantil, que el edificio sea "feo". O bien, aprovechando la elocuencia de la expresión española, que sea arquitectónicamente amorfo; es decir, sin forma arquitectónica. En jerga vanderliana, diríamos que durante nuestro segundo septenio despierta nuestra sensibilidad estética y por lo tanto demandamos que las formas que pueblan el universo urbano cumplan con las leyes de la percepción visual. (p. 85)

Desde la perspectiva internacional, gracias a los estudios realizados por Burke y Grosvenor (2003) conocemos algunas propuestas arquitectónicas de estudiantes que plantean la escuela que les gustaría tener. $\mathrm{Y}$ entre las categorías que hallan destacan las siguientes:

- Membrana exterior, como una celda, que es penetrable y permeable a la luz, transparente y que atrae la vista del público.

- Construcción coherente con la forma en espiral propuesta por Bruner en 1996 para concebir un curriculum que sugiere el modo en el que el aprendizaje aumenta curso a curso reiterando conocimientos cada vez más profundamente.

- Ambientes de ocio (cúpulas y bóvedas).

- Versatilidad, posibilidad de cambio y adaptación.

- Organización de la autoridad y control.

- Confort, privacidad, espacio para actividades sociales y descanso, colorido, de suaves texturas que invitan al interior.

Sin embargo, desconocemos en el contexto español cuáles pueden ser los planteamientos de la población estudiantil, pues no hemos hallado en la revisión de la literatura estudios orientados a recoger sus opiniones. Esta opción es plausible en la medida en que nos encontramos "en un interesante momento de tensión en el cual los colegios y las aulas evidentemente necesitan ser reinventadas y redefinidas pero parecen estar atrapadas en formatos diseñados en una época anterior" (Burke, et al., 2006, p. 02). Por todo ello es importante reflexionar sobre las escuelas que deseamos tener y la estética que las va a configurar. Para ello estudiaremos dos focos de interés, la arquitectura escolar y los patios de recreo, por ser los lugares donde el colectivo estudiantil pasa más tiempo.

\footnotetext{
4 "At an interesting moment of tension in which schools and classrooms evidently need to reinvent or redefine themselves but appear to be trapped in formats designed for an earlier age" (Burke, et al., 2006, p. 2).
} 


\subsection{La arquitectura escolar}

La arquitectura escolar define las condiciones de confort en las que van a desarrollarse los procesos de enseñanza aprendizaje. Y también ocurre a la inversa, existe "una relación entre el desarrollo infantil, la práctica educativa, y las implicaciones de estos factores en el diseño" (Burke, Gallagher, Prosser y Torrington, 2006, p. 1). Pedagogía y espacio se conciben como una unidad a la hora de diseñar (Fisher, 2005). Sin embargo, los aspectos a los que prestan atención los arquitectos cuando proyectan los edificios escolares, no parecen ser los mismos asuntos observados por quienes enseñan o por quienes aprenden. Una mejor comunicación entre agentes implicados en el diseño y el uso posterior, es precisa si deseamos espacios de calidad para la educación. Por ello, la investigación se presenta como un medio facilitador en este sentido, pues arroja luz sobre los entornos deseados por escolares.

Varios autores (Gutiérrez Pérez, 1998; Ruiz Ruiz, 1994 y Heras Montoya, 1997) son unánimes en la necesidad de considerar que es preciso prestar atención a la organización y al uso del espacio físico y, que este es también, un factor decisivo de motivación, de interés, de participación y de integración de personas. Ha sido referida por algunos autores (Crespo Comesaña e Pino Juste, 2003, 2009) la importancia de la arquitectura del espacio escolar en la formación de alumnos, así como su importancia en la calidad de vida y también ha sido evidenciada (Aznar e Pino Juste, 2009; Pino Juste e Bezerra Barbosa, 2007) (Bezerra Barbosa y Pino-Juste, 2011, p. 97).

En cuanto a los aspectos arquitectónicos, también la organización de las aulas es relevante. Esta "incluye tanto la ordenación de los elementos delimitadores del espacio físico -ubicación y edificio- como los que conforman su interior -equipamientos y material didáctico-"(Gairín Sallán, 1995, p. 1), imágenes en los muros (Huerta, 2015). Según la literatura revisada, los focos de interés son distintos en el reto de organizar los espacios. Cepeda, Lara, Serrano, González y Heredero (2010) consideran primordial la organización por áreas de trabajo o rincones, la organización de los materiales, las zonas destinadas a la privacidad, las distribuciones individuales, por parejas, en grupos, en forma de $\mathrm{U}$.

En todo centro educativo, el aula no debe ser solo un telón de fondo del aprendizaje de los alumnos y poco a poco se está admitiendo una gran influencia de las medidas que se adoptan en este contexto.

Tanto las variables organizativas como la disposición establecida intervienen de forma decisiva en la forma de enseñanza elegida (Cepeda, et al., 2010, p. 2). 
Naranjo (2011) distingue entre espacios de tareas escolares y espacios distractores, y con ello desmonta la supuesta distribución 'natural' que comparten la mayoría de diseños áulicos que en realidad pretenden aislar al estudiantado de otros espacios distractores como la calle o el patio. Otros investigadores como Pérez y Córdoba (2015) diferencian simplemente entre zonas permanentes - en las que las tareas son similares en casi todas las sesiones y en el mismo lugar a lo largo del año escolar - y zonas funcionales apartados destinados a investigación y práctica educativa para trabajar cooperativamente, de forma autónoma o vivencial —. Una distinción similar a la propuesta por Gairín Sallán (1995) al referirse a espacios fijos y espacios no estructurados.

\subsection{Los patios de recreo}

Las instalaciones educativas van más allá del edificio o de las aulas y cabe considerar la organización y usos de otros espacios donde también transcurre parte del tiempo lectivo infantil, como son los patios de recreo. Esto supone combinar el foco de atención pedagógico de la plantilla docente, la mirada arquitectónica del equipo proyectista y la revisión del grupo de menores, pues las necesidades de los tres colectivos ponen el cuidado en entornos diferentes.

Miranda, Larrea y Muela (2014), en un estudio sobre los espacios exteriores en 20 centros educativos de la provincia de Guipúzcoa, reconocen, en estos lugares, las siguientes características: [1] centrados en los deportes mayoritarios, [2] pobres en propuestas y recursos, [3] concebidos por docentes para que sus pupilos y pupilas corran, se desfoguen y se cansen, [4] sin contacto con la naturaleza, y [5] de uso limitado en tiempo y espacio. Es preciso reflexionar si estas propiedades son comunes a la mayoría de escuelas españolas, o al menos las públicas; pues están sujetas a la calidad estética de los espacios educativos y por ende, a la calidad educativa.

En este sentido, Miranda, Larrea, Muela, Martínez de Lagos y Barandiaran (2015) insisten en la integración curricular del espacio exterior e inciden en "la importancia de valorar el espacio exterior escolar como un recurso pedagógico muy útil que puede influir positivamente en el desarrollo psicosocial de los niños y las niñas" (p. 161). Por su parte, Gallart (2008), además de este papel educativo y recreativo, reconoce el emotivo, organizativo e interactivo para el desarrollo integral del estudiantado. Mientras que Marín (2012) abunda en el rol educativo pero también en el lúdico. En este sentir pedagógico del uso del patio, son destacables las iniciativas de algunas escuelas infantiles Equip de 
l'Escola Bressol Municipal Els Belluguets (2010), Equipo educativo EEI Platero, (2006), Escola Emili Vallès, (Rota, 2014); sin embargo, estas zonas de juego para escolares de primaria todavía parecen desaprovecharse en líneas generales.

Desde la perspectiva de género, existe coincidencia en la comunidad científica en que las zonas de juego del patio se distribuyen de forma jerárquica y desigual (Cantó Alcaraz y Ruiz Pérez, 2005; Rodríguez Navarro y García Monge, 2009).

Si el adulto no interviene, los niños en general y los mayores en particular tienen más posibilidades de disponer de los espacios más amplios y de realizar los juegos más prestigiosos dentro de los códigos elaborados por el alumnado (deportes). Esta segregación y jerarquización en los espacios se recoge también en trabajos como los de Geertz (1992) o Martínez y García (1997); Cantó y Ruiz (2005); Rodríguez, Retortillo y García (2007). Algunas explicaciones de esta invasión espacial hacen referencia a la reproducción los juegos infantiles de ciertos rasgos culturales reforzados en función del género. (Rodríguez Navarro y García Monge, 2009, p. 65).

Sin embargo, poco sabemos de los deseos, de que quienes aprenden, sobre la distribución, características y funciones de su patio. Es por ello que resulta pertinente la investigación acerca de los deseos y anhelos proyectados también sobre el espacio exterior escolar.

\section{Metodología}

Desde la perspectiva del estudio de la calidad estética de los entornos educativos y concretamente centrados en la búsqueda de factores determinantes de la experiencia estética desde el punto de vista discente, el objetivo consiste en establecer qué elementos ausentes en el entorno escolar serían necesarios para un mayor confort y calidad educativa, así como qué elementos presentes en el entorno escolar sería preciso eliminar o modificar para una mayor comodidad.

Resulta ineludible considerar la sala de clases como uno de esos espacios rutinarios que deben ser explorados estéticamente, tomando en cuenta no sólo sus características placenteras, sino también aquellas que resultan desagradables 0 inapropiadas en el contexto escolar. (Errázuriz-Larraín, 2014, p. 137) 
No procuramos dar respuesta a un problema, sino generar un producto teórico de índole estético sobre el entorno escolar deseado frente a los elementos existentes equívocos, así como información sobre el proceso de diseño que aporte directrices para guiar futuros diseños.

Por una parte, se persigue averiguar si el modelo teórico permanece viable a la vista de los datos obtenidos y, por otra, se valora la posible necesidad de modificar el modelo ante observaciones inesperadas. Para lograr este propósito doble, vamos a analizar el aprendizaje en su contexto real mediante el diseño y estudio sistemático de formas particulares de aprendizaje artístico a través de estrategias y herramientas de enseñanza basadas en el trabajo colaborativo (Johnson y Johnson, 1975), las inteligencias múltiples en el aula (Armstrong, 2006) y el modelo de Jonassen (1994) para el diseño de ambientes de aprendizaje constructivistas.

En este trabajo es sensible a la naturaleza sistémica de los procesos educativos y de la evaluación en artes (Aguirre, 2005; Hernández-Hernández, 2010) en tres escuelas diferentes, con un interés por comprender y mejorar la realidad educativa. En una situación que comprende a una investigadora -formadora de profesorado en especialidad de artes-, quien trabaja en aulas en colaboración con sus docentes responsables - agente externa que realiza una inmersión en un contexto de aprendizaje-enseñanza - Todo ello enmarcado en un paradigma, considerado por Molina, Castro, Molina, y Castro (2011), potente en la investigación del aprendizaje y la enseñanza: la investigación de diseño, "que persigue comprender y mejorar la realidad educativa a través de la consideración de contextos naturales en toda su complejidad y del desarrollo y análisis paralelo de un diseño instruccional específico" (p. 75). Además, como recogen estos autores, en nuestro caso "sucesivas aplicaciones y elaboraciones del diseño son realizadas en contextos diferentes o incluso en niveles diferentes desde la visión del diseño curricular (aula, centro, sistema educativo, formación de profesores)" (p. 77), pues se trabaja con 7 cursos de 3 colegios.

Dentro de este paradigma, la metodología seguida debe aproximarse a las capacidades comunicativas de cada población. Si pertenecen a cursos de infantil y primaria, pueden encontrar en el lenguaje visual y en el lenguaje corporal una vía de comunicación complementaria a la verbal que no podemos descuidar.

Es por ello que empleamos la investigación educativa basada en las Artes Visuales (Marín, 2005; Marín y Roldán, 2008, 2009, 2010) durante la recolección de datos, y la Investigación Basada en Imágenes (Marín, 2005) durante el análisis de datos. De modo que, 
a partir de dibujos u otro tipo de creaciones artísticas del estudiantado, se recogen las opiniones e inquietudes del colectivo estudiantil con respecto al espacio educativo que les rodea (Burke, et al., 2006). La forma de proceder depende de la edad de quienes participan del estudio y de su capacidad de ejecución, pues consiste en pedirles que se expresen artísticamente. Del análisis de las imágenes es posible extraer categorías y códigos emergentes que nos aproximen a aquello que les gusta o les disgusta y a aquello que detestan, desean o anhelan en su entorno.

\subsection{Población}

En una apuesta por una epistemología etnológica de la observación, valoramos el contacto efectivo con interlocutores, la representatividad cualitativa del grupo elegido (situando desde esta perspectiva conceptos como el de etnia), la capacidad de generalización (desde la exploración de un caso singular que remite a la elaboración de configuraciones que exceden ampliamente ese único caso), la legitimidad de la antropología de la contemporaneidad cercana y la alteridad íntima (Auge, 2000, pp. 20-26). Este posicionamiento va a dar cuenta de los criterios considerados para la selección de los centros educativos donde se desarrolla el estudio. Consisten en que:

- Sean Centros de Educación Infantil y Primaria públicos ubicados en la Comunidad Valenciana, concretamente en la ciudad de Alicante.

- Sean escuelas abiertas a un contacto directo entre investigador, estudiantado y profesorado en el interior de las aulas.

- Ofrezcan diversidad de "poblados". Por ejemplo, minoría étnica como es la población gitana, linaje de feriantes, comunidad multicultural por procesos migratorios...

- Sean representativas de otras escuelas de la misma tipología. Por ejemplo, escuela urbana, escuela rural, CAES. En relación con la influencia del entorno donde se ubica el centro (Cabezas y Monge, 2014).

- Estén inmersas en procesos de cambios contemporáneos. Por ejemplo, afrontamiento de riesgo de desaparición, solicitud de ampliación, tramitación de nuevo emplazamiento.

- Ofrezcan una identidad colectiva vinculada a la identidad individual de sus miembros. 
Tabla 1. Características de las escuelas donde se desarrolla la investigación

\begin{tabular}{|c|c|c|c|}
\hline Colegio & $\begin{array}{l}\text { CEIP Cañada del } \\
\text { Fenollar }\end{array}$ & CEIP José Carlos Aguilera & $\begin{array}{l}\text { CEIP Maestro López } \\
\text { Soria }\end{array}$ \\
\hline $\begin{array}{l}\text { Año } \\
\text { construcción }\end{array}$ & 1970 & 1976 & 1974 \\
\hline $\begin{array}{l}\text { Emplazamient } \\
\text { o }\end{array}$ & $\begin{array}{l}\text { Zona rural de } \\
\text { expansión de la ciudad } \\
\text { no urbanizada }\end{array}$ & Centro urbano. & $\begin{array}{l}\text { Gueto. Centro de Acción } \\
\text { Educativa Singular } \\
\text { (CAES) }\end{array}$ \\
\hline Dirección & $\begin{array}{l}\text { Ctra Alcoraya-urbs } 50 . \\
03699 \text { de Alicante. }\end{array}$ & $\begin{array}{l}\text { C/ Médico Pedro Herrero } \\
\text { 5B. } 03006 \text { de Alicante. }\end{array}$ & $\begin{array}{l}\text { Avda. Alcalde Lorenzo } \\
\text { Carbonell, 3. } 03008 \text { de } \\
\text { Alicante. }\end{array}$ \\
\hline $\begin{array}{l}\text { Referencias } \\
\text { catastrales }\end{array}$ & $\begin{array}{l}001306600 \mathrm{YH} 15 \mathrm{C} 0001 \\
\text { MO } \\
001306700 \mathrm{YH} 15 \mathrm{C} 0001 \\
\text { OO } \\
001306800 \mathrm{YH} 15 \mathrm{C} 0001 \\
\text { KO }\end{array}$ & $\begin{array}{l}\text { 8371505YH1487A0001TU } \\
\text { 8371510YH1487A0001MU }\end{array}$ & $\begin{array}{l}\text { 8364504YH1486C0001X } \\
\text { I }\end{array}$ \\
\hline $\begin{array}{l}\text { Evolución } \\
\text { constructiva }\end{array}$ & $\begin{array}{l}2006 . \quad \text { Ampliación } \\
\text { provisional mediante } \\
\text { barracones } \\
\text { prefabricados } \\
\text { 2016. Compromiso de } \\
\text { traslado a un nuevo } \\
\text { emplazamiento } \\
\text { cercano, todavía sin } \\
\text { proyecto de ejecución. }\end{array}$ & $\begin{array}{l}\text { 2012. Ampliación zona de } \\
\text { comedor y patio de } \\
\text { recreo. } \\
\text { 2016. Con necesidades de } \\
\text { remodelación de espacios } \\
\text { y ampliación }\end{array}$ & Invariable \\
\hline $\begin{array}{l}\text { Número de } \\
\text { líneas }\end{array}$ & $\begin{array}{l}1 \\
\text { (antes } \\
\text { unitaria) }\end{array}$ & 1 & 1 \\
\hline $\begin{array}{l}\text { Perfil del } \\
\text { estudiantado }\end{array}$ & $\begin{array}{l}\text { Mayoría proveniente } \\
\text { de familias nacionales } \\
\text { y feriantes }\end{array}$ & $\begin{array}{l}\text { Mayoría proveniente de } \\
\text { familias inmigrantes }\end{array}$ & Etnia gitana \\
\hline
\end{tabular}

Fuente: elaborado con la información recolectada en la investigación a partir de entrevistas a las directoras y director de las escuelas, los Proyectos Educativos de Centro, así como la web del Catastro virtual https://www1.sedecatastro.gob.es

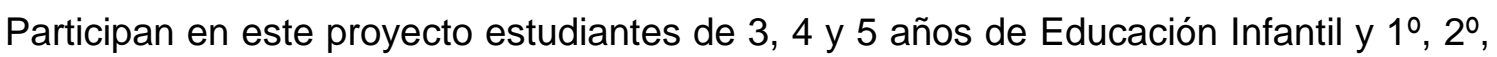
3ำ 4ํ de Educación Primaria de las tres escuelas públicas de Alicante mencionadas en la tabla 1. Estos 324 participantes (según las faltas de asistencia, el número puede variar levemente) han disfrutado de tres sesiones previas a esta, en las que han profundizado en las experiencias estéticas cotidianas escolares a través de la relación que se establece con el entorno mediante los sentidos y el movimiento corporal. Además han reflexionado sobre sus lugares preferentes en el colegio y las emociones que les generan. Estas acciones anteriores sirven, desde el punto de vista didáctico, como preparación para enfrentarse a la 
cuestión de investigación en la que se les implica para este estudio, y que, con ello, puedan ofrecer así respuestas más meditadas y conscientes.

Tabla 2. Número de participantes por curso de los colegios CEIP Cañada del Fenollar, CEIP José Carlos Aguilera, CEIP Maestro López Soria de Alicante, España entre los meses de octubre de 2015 y mayo de 2016.

\begin{tabular}{|c|l|l|l|l|}
\hline \multicolumn{2}{|c|}{$\begin{array}{c}\text { Colegio } \\
\text { Curso }\end{array}$} & $\begin{array}{l}\text { CEIP Cañada del } \\
\text { Fenollar }\end{array}$ & $\begin{array}{l}\text { CEIP José Carlos } \\
\text { Aguilera }\end{array}$ & $\begin{array}{l}\text { CEIP Maestro López } \\
\text { Soria }\end{array}$ \\
\hline \multirow{3}{*}{ Infantil } & 3 & 14 & 18 & 8 \\
\cline { 2 - 6 } & 4 & 12 & 21 & 5 \\
\cline { 2 - 6 } & 5 & 9 & 12 & 13 \\
\hline \multirow{4}{*}{ Primaria } & $1^{\circ}$ & 21 & 28 & 9 \\
\cline { 2 - 6 } & $2^{\circ}$ & 17 & 17 & 11 \\
\cline { 2 - 6 } & $3^{\circ}$ & 24 & 28 & 5 \\
\cline { 2 - 5 } & $4^{\circ}$ & 24 & 19 & 9 \\
\hline \multirow{2}{*}{ Total } & 121 & 143 & 60 \\
\hline
\end{tabular}

Fuente: elaborada a partir del recuento de los trabajos artísticos entregados en cada aula y escuela por cada participante, 2016.

\subsection{Recolección de datos}

Los instrumentos de recopilación de datos son técnicas de expresión artística como el dibujo y el collage, empleadas en los métodos visuales de investigación. La formación de la investigadora tanto en artes como en arquitectura y didácticas específicas garantiza el diseño instructivo.

La elaboración de un diseño instructivo requiere que el investigador pueda anticipar y comprender cabalmente el modo en que los diversos elementos que interactúan en la clase podrían afectar el curso de los aprendizajes (Walker, 2006). Se comprende entonces la gran importancia que adquiere el conocimiento disponible, tanto acerca de la disciplina en torno de la cual se elabora el diseño como sobre la naturaleza de los procesos de aprendizaje que se espera favorecer (Rinaudo, y Donolo, 2010, p. 6).

Se les propone dibujar el edificio escolar, aula o patio que les gustaría tener; y de este modo se obtienen como respuestas las voces visuales de escolares. Los dibujos pretenden recoger los anhelos y deseos proyectados sobre uno de estos tres lugares, dejándose a libre elección de quienes participan del estudio uno de estos focos de interés.

Inicialmente, se les entrega una hoja DIN A3 donde poder proyectar el entorno educativo deseado. A los cursos de infantil les decimos que imaginen que tenemos una varita mágica que pudiera hacer realidad todo lo que dibujen; a los cursos de primaria se les 
hace entender que es muy importante que compartan con la población adulta sus voluntades porque solamente así podrán ser atendidas por quienes proyectan las escuelas, y que aunque no se tenga en cuenta inmediatamente podrá beneficiar en el futuro a escolares de cursos inferiores. Se les invita a reflejar todo aquello con lo que no cuentan actualmente sus centros, pero que desearían que estuviera presente para un mayor placer, gusto y disfrute. También se les incita a no incorporar cualquiera de las cosas que aunque ahora existan en su escuela, les disgustan o desagradan.

Incentivamos su creatividad recordándoles que para conformar esos criterios estéticos experimentan a través del tacto, el gusto, el olfato, el oído, la vista lo que tienen a su alrededor (es algo que descubren previamente en una primera sesión de trabajo). Y así mientras van dibujando se les plantean interrogantes inspiradores, pidiéndoles no responder en voz alta, sino dibujando, para que cada uno se exprese de manera desenvuelta:

- ¿Cómo sería la temperatura para encontraros cómodos: mucho calor, mucho frío, templada, con sol y/o sombra...? ¿Y el tacto del suelo, de las paredes, del techo: áspero, suave, blando, duro, rugoso...? Conviene no olvidarse pues de reflejar las cosas que nos van a hacer sentir así.

- ¿A qué va a saber? Que no se nos olvide mostrar los sabores de nuestro patio o clase.

- ¿Cómo tendría que oler la clase o el patio para que os gustara? Pues poned aquello que desprenda ese olor y quitad lo que haga que huela diferente.

- ¿Qué se escucharía? Entonces dibujad lo necesario para que puedan estar esos sonidos o para no oír otros que os disgustan.

- ¿Cómo se va a ver esa clase o patio: grande, pequeño, feo, bonito, colorido...? Acordaos de no dibujar lo que haga que se vea distinto y de añadir lo que falta para que os guste mirarlo.

Conseguir una respuesta rica en matices, detalles y compleja depende de que quienes colaboran con nosotras no se cansen pronto ante la hoja y sientan el deseo de seguir dibujando. Es por ello que mientras ejecutan la tarea se les sigue estimulando con preguntas relacionadas con lo que han averiguado en las sesiones anteriores; por ejemplo, en una segunda sesión sobre la forma de relacionarnos corporalmente con lo que nos rodea:

- ¿Cómo os gusta moveros por este espacio: corriendo, andando despacio, arrastrándoos, saltando, trepando, volando, nadando, escalando, deslizándoos, gateando...? Diseñad todo lo necesario para poder moveros como deseáis. 
- ¿Con qué, con quién o quiénes nos gusta movernos? Pensad si os hacen falta objetos, animales, plantas o personas en ese lugar para estar bien.

Se emplean variedad de sinónimos para expresar estas ideas porque no sabemos cuál será la palabra que actúe como detonante de una imagen para cada individuo, nunca se les propone una única opción y cuando se dan alternativas se procura incorporar tanto conceptos similares como opuestos. Estas cuestiones son importantes porque no queremos que crean que hay una respuesta válida que nosotras (maestras e investigadora) estamos esperando que den, sino que comprendan que cada cual tiene su visión y deseos diferentes.

Alcanzado el punto de saturación, es decir, agotadas las nociones que de forma libre emergen en sus dibujos, de modo similar a las entrevistas de respuesta abierta; esta forma de recoger las opiniones del estudiantado deja de tener un cariz cualitativo y se torna más cuantitativa. Buscamos continuar incorporando riqueza a la consulta, pero esta vez a partir de respuestas prediseñadas, de modo análogo a las entrevistas de respuesta cerrada. Para tal fin se les facilita una hoja adhesiva de tamaño DIN A3 que incluye gran cantidad de imágenes lineales en blanco y negro, variadas en cuanto a nociones y tipologías, incluso estilos y que representan objetos cotidianos o decorativos, mobiliario, juegos, infantes, alimentos, animales, plantas...

En la elaboración de estas pegatinas se procura incluir elementos muy dispares, incluso los que previsiblemente no parece que se vayan a desear incorporar, pues tenemos que dar opción a que deseen descartar respuestas. Pensemos que una criatura ante una hoja de pegatinas puede tender a querer adherir todas, una detrás de otra, y se trata de que tengan un criterio de selección consciente. Así que se les advierte que todas no tienen por qué servir, que deben decidir cuáles son importantes y cuáles están ahí para confundirles. También se condiciona el tiempo de trabajo para limitar el collage a aquellos elementos que realmente les resultan más atractivos. Además, se les permite seguir dibujando, es decir, estas respuestas dadas sirven también de detonante porque les recuerdan otros elementos importantes o porque se parecen a algo que no está disponible pero desean exponer en sus contestaciones. 
Figura 1. Elementos adhesivos facilitadores al alumnado.

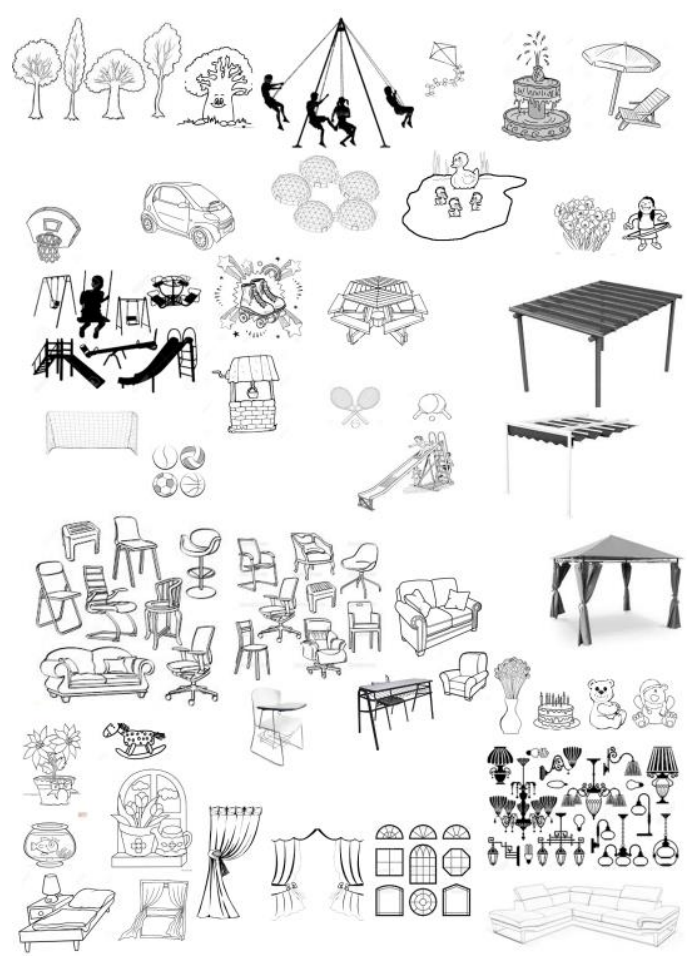

Fuente: elaborado a partir de una búsqueda en Google imágenes aplicando como filtro dibujo lineal, 2016.

Por último, se les pide incorporar color a sus dibujos con lápices de madera. En una tercera sesión, previa a esta actividad, el grupo de estudiantes ha aprendido a expresar pictóricamente sus emociones, de manera que están preparados no solamente para colorear, sino para hacerlo con una intención expresiva.

Estos tres pasos - dibujo, collage y pintura- (en ocasiones, las sesiones de tarde más breves solo permiten que sean los dos primeros) van marcando un ritmo cambiante para evitar que decaiga el interés del estudiantado y mantener despierta su voluntad de participación. De lo contrario, en los primeros 15 minutos, la atención habría desaparecido y las respuestas habrían sido pobres. Todas estas decisiones pedagógicas acompañan el diseño del instrumento de recogida de datos para un óptimo empleo de los métodos visuales. La implicación del estudiantado es extraordinaria y demuestran una gran intención comunicativa, únicamente un participante no halla en este lenguaje una vía óptima para expresarse, reemplazándolo por palabras -casualmente un infante de 3 años de edad (Lorenzo_3inf_CF)- 
Contamos con que es inevitable que cada participante mire a los demás y sus dibujos mientras trabajan; por ende, existe un contagio de ideas en la medida en que deciden incorporar algo que alguien ya ha trazado previamente y que también les gustaría agregar a su labor. Incluso en esos casos, existe una decisión y voluntad, y se construye una idea de colegio compartida, una idea colectiva, que es la que nos interesa dilucidar finalmente.

\section{Resultados y su análisis}

El análisis de los dibujos —que libremente crearon quienes participaron de esta investigación - se estudia tratando de reconocer categorías temáticas, preocupaciones compartidas y rasgos comunes tanto estilísticos como conceptuales. Los resultados provienen de un rango etario que va aproximadamente de los 3 a los 9 o 10 años de edad. Como consecuencia del carácter cíclico de esta investigación de diseño, generamos dos tipos de análisis de datos: Por un lado, análisis continuados realizados durante los diferentes ciclos o sesiones en cada aula/escuela, estos nos permiten modificar, en la acción, el modelo teórico, y observar diferencias según colectivos. Por otro lado, un análisis final retrospectivo de todos los datos recogidos en el proceso de investigación del que se da cuenta a continuación.

En primer lugar, se categorizan las repuestas por edad y solo con posterioridad de forma temática. Como consistencias dentro de los rangos etarios, la principal diferencia hallada es que entre los 3 y 6 años los dibujos se centran en diseños de los patios de recreo con alguna propuesta para el interior del aula; mientras que en edades superiores la dispersión de temas es mayor, aparecen como focos de interés, además del patio o el aula, las cubiertas del edificio, los materiales constructivos y la distribución espacial de diferentes edificios conformadores de la institución. Tal selección manifiesta, por tanto, una mayor madurez intelectual y emotiva en los cursos de primaria (que se corresponden con el segundo septenio). Por ello, se exponen primero los resultados que ofrecen categorías compartidas por ambos ciclos, y a continuación los que surgen de participantes exclusivamente del ciclo de primaria. 


\subsection{Análisis cualitativo}

Figura 2 Serie "toboganes"
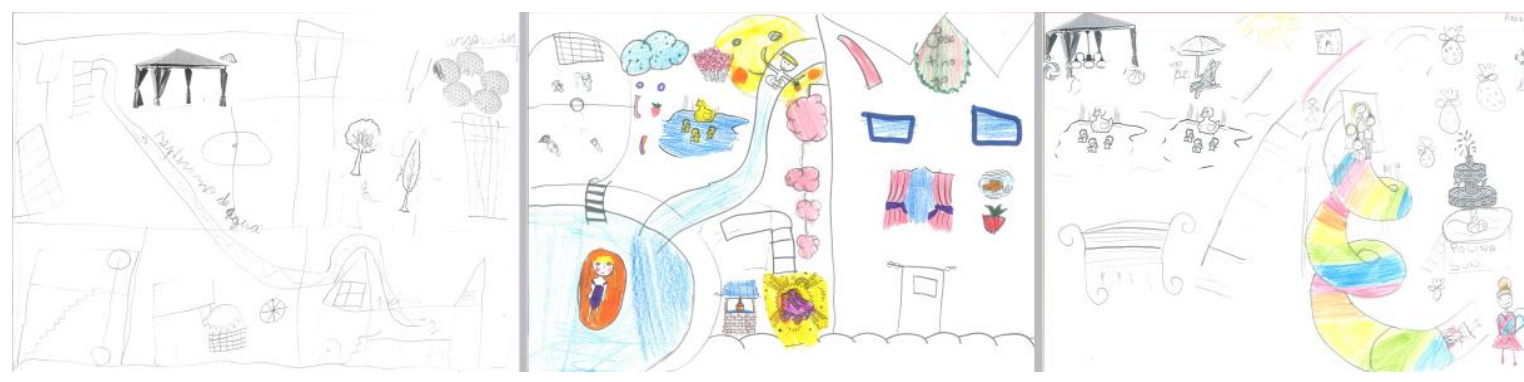

Fuente: elaborada a partir de los dibujos de Iñaki de 3 del CEIP Cañada del Fenollar, Kiara de 3 del CEIP José Carlos Aguilera y Arabia de 3ำ del CEIP Maestro López Soria, 2016.

Entre las respuestas abiertas, destaca que, prácticamente, la totalidad del estudiantado infantil demanda la presencia de toboganes, un juego que ya es común en los tres patios existentes (Macarena_4inf_MLS), (Ainhoa_3inf_CF), y también los dibujan con mayores longitudes, como método para bajar de las clases, como juego en el patio o en la piscina (Martín_4inf_CF), (Iñaki_3﹎_CF), (Brayan_5inf_MLS), (Arabia_3﹎MLS), (Izan_3ㄴ_JCA), (Kyara_3o_JCA), (Laura_3o_JCA) [ver figura 4]. Mientras que la presencia de esta necesidad en cursos superiores parece menor, posiblemente porque la evolución cognitiva y física del infante genera intereses diferentes a medida que incrementa su edad.

Figura 3. Serie muestra "juegos y descanso"
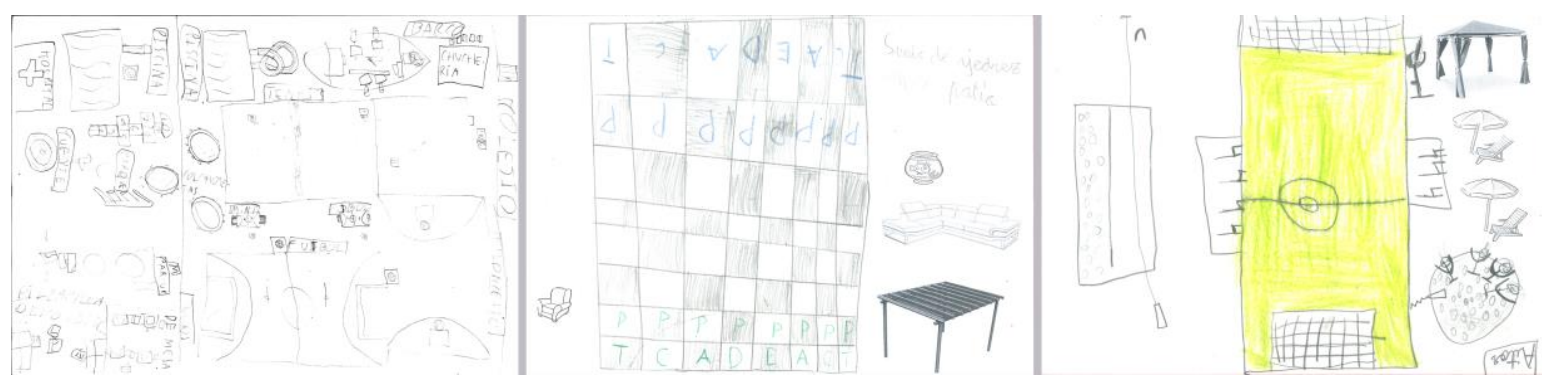

Fuente: elaborada a partir de los dibujos de Daniel de $4^{\circ}$ y Aitor de $2^{\circ}$ del CEIP Cañada del Fenollar, y Aaron de $2^{\circ}$ del CEIP José Carlos Aguilera, 2016. 
En la misma línea de estéticas lúdicas, una buena parte de la población participante plantea patios repletos de estímulos sensoriales, materiales y juguetes con los que entretenerse, como colchonetas hinchables, tirolinas, campos de voleibol o hockey, pista de baile, tubo de bomberos, rocódromos, circuitos bmx (Chema_4inf_CF), (Hugo_4inf_CF),

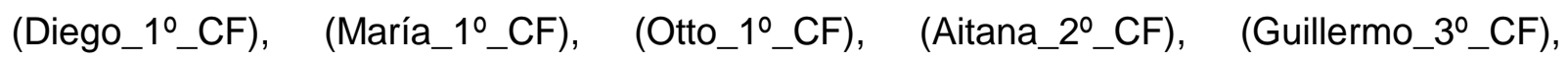

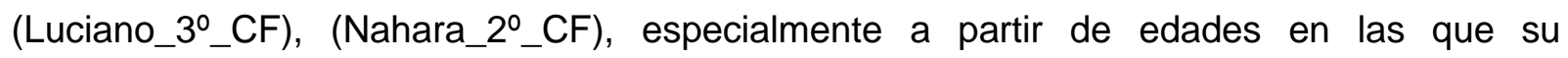
motricidad gruesa mejora. También incorporan juegos pintados en el suelo como: rayuelas, (Ana María_5inf_CF), (Daniel_4으CF), (Lenka, 5inf_JCA), juegos de ajedrez (Aaron_ํ﹎CA)

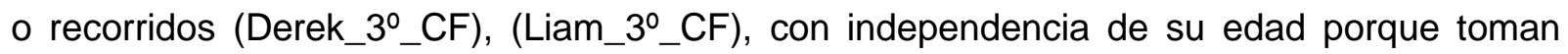
como referencia algunos ejemplos que ya existen en sus centros. Pero también anhelan, en los patios de primaria, espacios de descanso y relajación con sofás, spa y tumbonas

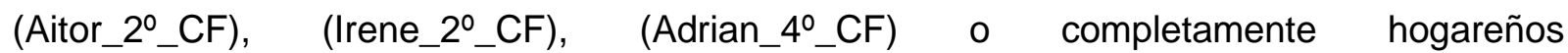
(Stefhanie_4으CF) (ver figura 5).

Se trata de una proyección que se aleja de la realidad con la que conviven, aunque los escasos recursos con que cuentan son rescatados y mantenidos en los dibujos de los más pequeños; por ejemplo el hipopótamo, las pelotas, cochecitos y ruedas del patio de infantil del CEIP Cañada del Fenollar (Ruben_4inf_CF), la tortuga de juguete del patio de infantil del CEIP Maestro López Soria (Dolores_5inf_MLS), (Elisa_5inf_MLS), (Elisabet_5inf_MLS) o los mencionados toboganes de las tres escuelas. Se demuestra así que, mientras que en cursos superiores saben generar actividades lúdicas a pesar de carecer de objetos de carácter simbólico o juegos, no es así para quienes tienen menor edad. Estas demandas infantiles son coherentes con los resultados mostrados por Miranda, et al. (2015) al describir los patios escolares españoles:

Escasas las propuestas de juego y recursos complementarios. Pocos eran los patios que ofrecían otros materiales de juego (cuerdas, sacos, columpios, motos...). Además, apenas existía una oferta complementaria que pudiera responder a los diversos intereses de los niños y las niñas para, por ejemplo, trepar, esconderse o pintar. (p. 162) 
Figura 4. Serie muestra "animales"
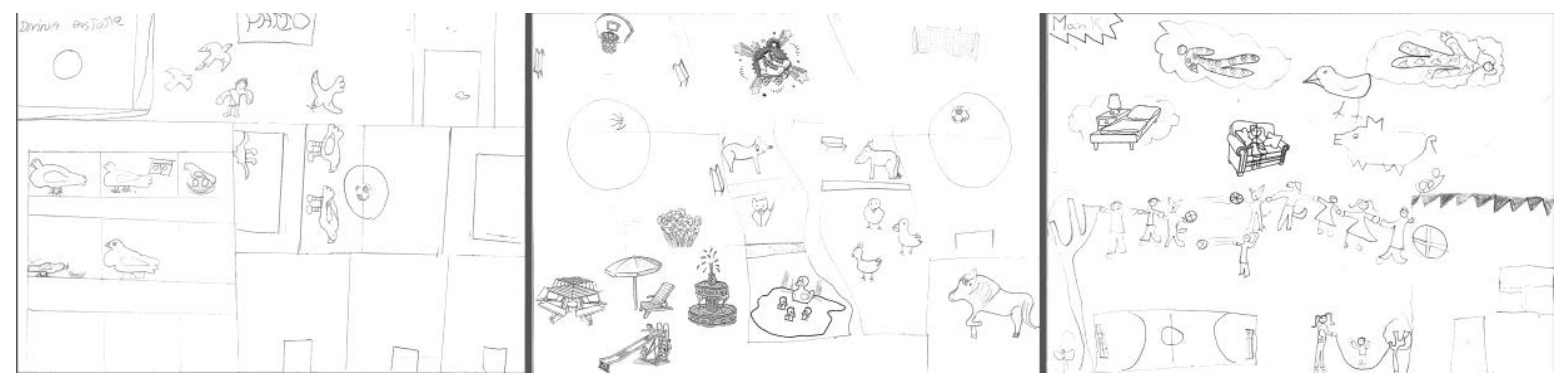

Fuente: elaborada a partir de los trabajos de: Manik de 3ํ del CEIP Cañada del Fenollar, Tyana de 3ํㅡㄹ del CEIP José Carlos Aguilera, e Ismael de 4ํㅜ curso del CEIP Maestro López Soria, 2016.

La tradicional concepción de las escuelas es cuestionada por este grupo de estudiantes, por ejemplo cuando plantean la convivencia con especies animales; una alternativa más próxima a la naturaleza y sus estímulos sensoriales que sin ser imposible no es común ni en las zonas urbanas ni en las rurales (Manik_3ํㅡㄷ), (Daniv_4ํㅡㄷ), (Ainhoa_3ㄴJCA), (Tyana_3ํJCA), (Jeni_3ํJCA), (Luis_3inf_MLS), (Ismael_4ํMLS) ([ver figura 8). Otra forma de cuestionar la escuela es desde la función que debe cumplir, pues aunque desde la perspectiva del adulto es un lugar para recibir una educación, desde la perspectiva del discente es también un lugar para recibir afectos, generar apegos y establecer amistades (Janet_5inf_CF), (Miriam_5inf_CF), (Moises_5inf_CF), (Zaira_3CF), (ElenaLeyda_3inf_JCA), especialmente entre los 3 y 6 años donde la madurez afectiva es menor. Destacan también los casos de quienes enfatizan la relación con otras personas producida en las instalaciones educativas (Debora_4inf_CF), subrayan así, los encuentros con iguales como elementos sustanciales de la configuración espacial. Este aspecto es especialmente destacable en el CEIP Maestro López Soria, donde observamos que los resultados son coherentes con el perfil de esta población; pues la propia cultura gitana cobija las relaciones familiares y los nexos comunitarios (JuanLuis_3inf_MLS), (Lorena_3inf_MLS), (Antonio_4inf_MLS), (Samira_4inf_MLS), (MaríadelMar_5inf_MLS), (Vanesa_5inf_MLS),

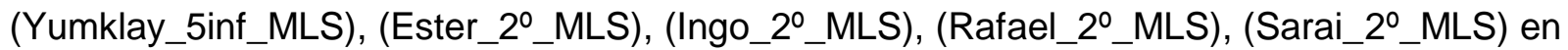
todas las edades.

A pesar de no haber sido posible obtener inferencias según edades entre los resultados, desde el punto de vista cromático, cabe resaltar que en aquellos casos en los que el estudiantado ha podido introducir color (por cuestiones organizativas de las sesiones no a todos les daba tiempo) lo ha hecho de dos modos: simbólicamente a través de colores saturados y con tonalidades que transmiten emociones positivas (Soraya_ ํ﹎MLS), 
(Tabita_3﹎_MLS), (Lucía_3inf_CF), (Noemi_3inf_CF), (Melina, 5inf_CF) [ver figura 9]; o bien mediante mímesis de la realidad (Miguel_1﹎MLS), (Valeria_4inf_CF). En cuanto a la orientación del formato del papel, predominantemente es horizontal, como una visión paisajística del lugar que, en algunos casos, se exacerba (Moaad_2ํ﹎JCA), (Victoria_2oㅡ, JCA).

Figura 5. Serie muestra "color simbólico"

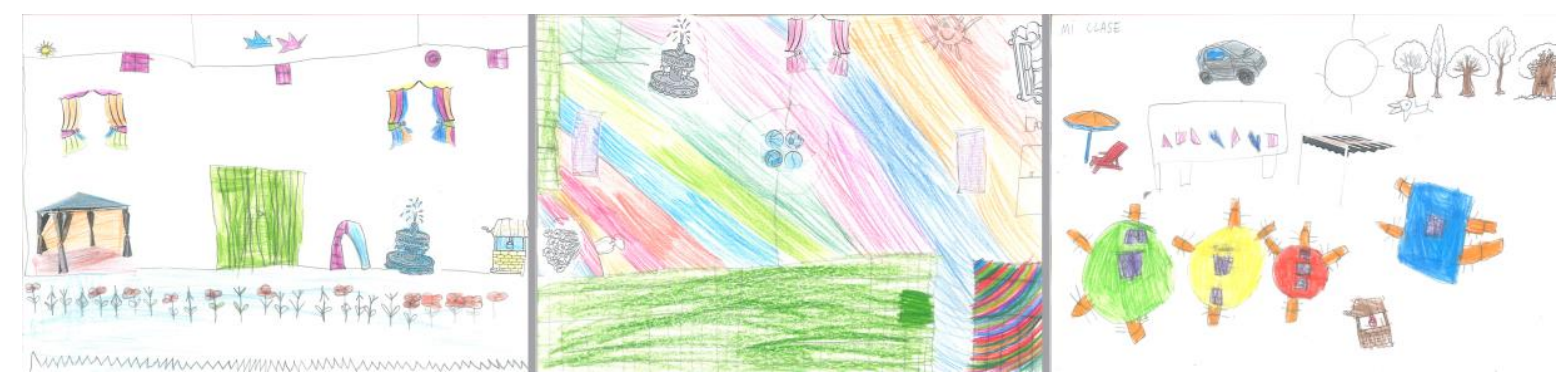

Fuente: elaborada a partir de los dibujos de Soraya de $2^{\circ}$ y Tabita de $3^{\circ}$ del CEIP Maestro López Soria y Melina de 5 años de infantil del CEIP Cañada del Fenollar, 2016.

EI CEIP Maestro López Soria devuelve resultados pobres en matices, escasos en demandas e incorporan menos elementos que tradicionalmente se consideran ajenos a los entornos escolares. Se trata de un colectivo de escolares sin diversidad de estímulos culturales que les permitan contrastar diversas realidades, permanecen aislados en un gueto con información limitada, y esta idiosincrasia se ve reflejada en sus respuestas.

Una de las cuestiones que también conviene observar es el tipo de respuestas que no emergen, aun siendo esperables en el contexto escolar. Es muy reducido el número de vallas, cercados o elementos delimitadores tanto entre áreas como en el contorno del lugar, apenas 3 casos, (JuanMiguel_3inf_CF), (anónimo_3﹎F); lo cual nos conduce a cuestionarnos, desde la voz visual infantil, la necesidad de estos elementos de control que rompen con la permeabilidad hacia el entorno. Por otro lado, en los dibujos, hay una ausencia completa de referencias a libros, materiales didácticos u otros útiles propios de la enseñanza. En su lugar, sin embargo, sí aparecen algunas pizarras, especialmente las digitales (Fatima_5inf_CF), ordenadores (anónimo_3ํCF), (Yenifer_1﹎_CF),

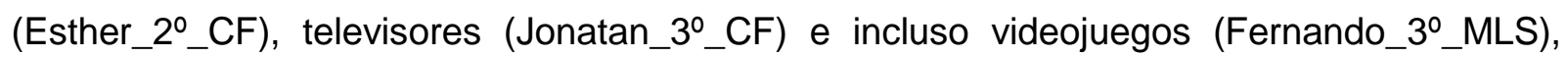
(Joffre_3﹎.JCA), pues con independencia de la edad toda la población ha tenido ya experiencias de aprendizaje con estos elementos tecnológicos. Esta visión infantil concuerda 
con la eterna discusión sobre la necesidad del empleo de libros de texto o su reemplazo parcial o total por otros materiales didácticos y metodologías.

Figura 6. Serie muestra "escuelas tradicionales"

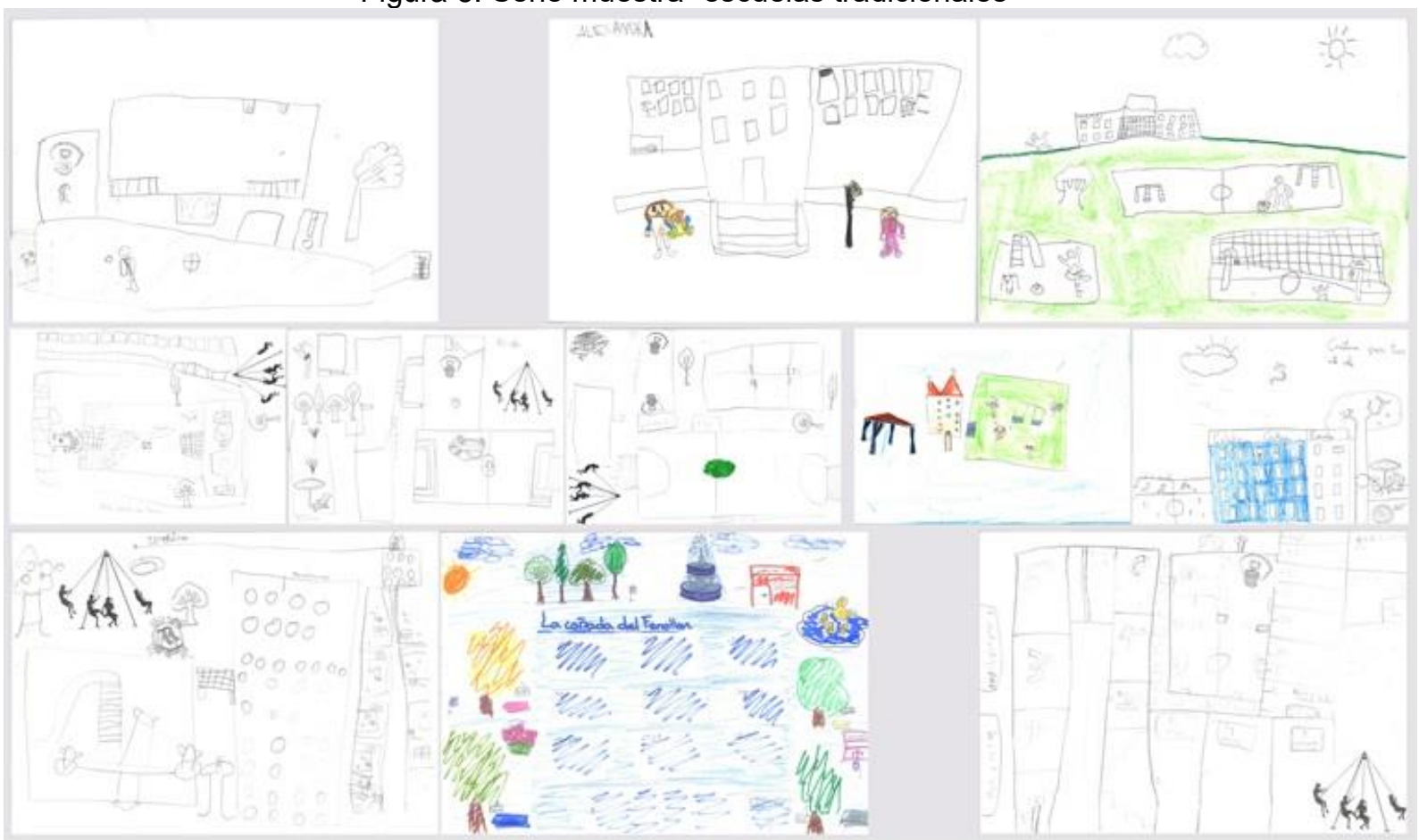

Fuente: elaborada a partir de los dibujos de: Miguel E., Adrià, Alfredo de 1ํㅡㄹ Eloi, Aitana y Celia de $2^{\circ}$, Haran de 4ํำ del CEIP Cañada del Fenollar; y Alexandra, Anhait, Jenny de $1^{\circ}$ y Cristina de $3^{\circ}$ del CEIP José Carlos Aguilera, 2016.

El grupo de escolares participantes es creativamente heterogéneo a la hora de imaginar soluciones diferentes a las que conocen. Por ello, por un lado se encuentran dibujos que son un fiel reflejo de las instalaciones educativas que utilizan (MiguelE_1으두) ${ }^{5}$, (Alexanda_1ํ_JCA), (Anahit_1ํ_JCA); en las que no existe mirada crítica alguna. Y otros que son versiones mejoradas de las instalaciones educativas de que disponen pero en los que los cambios propuestos son pequeñas aportaciones que no alteran sustancialmente la distribución o planteamiento existente. Por ejemplo, la añadidura de cubiertas al patio, zona

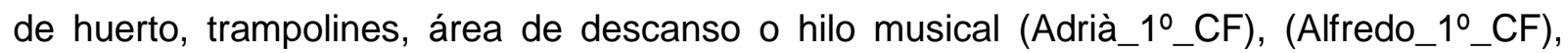

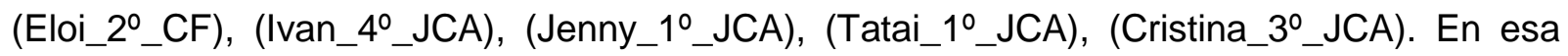
misma línea mimética, hallamos representaciones de la arquitectura escolar como reflejo de

\footnotetext{
${ }^{5}$ Se muestran entre paréntesis las referencias a los dibujos considerados dentro de esas categorías temáticas y que pueden servir como ejemplo, indicados del siguiente modo (nombre niño/a_curso_iniciales del colegio). Imágenes disponibles en http://tresescuelas.blogs.uv.es
} 
un programa curricular ascendente que otorga mayor conocimiento a los cursos superiores

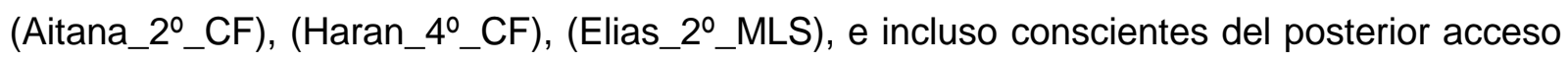
al instituto y la universidad (Celia_2으다). (Ver figura 2).

Figura 7. Serie muestra "cubiertas ajardinadas"

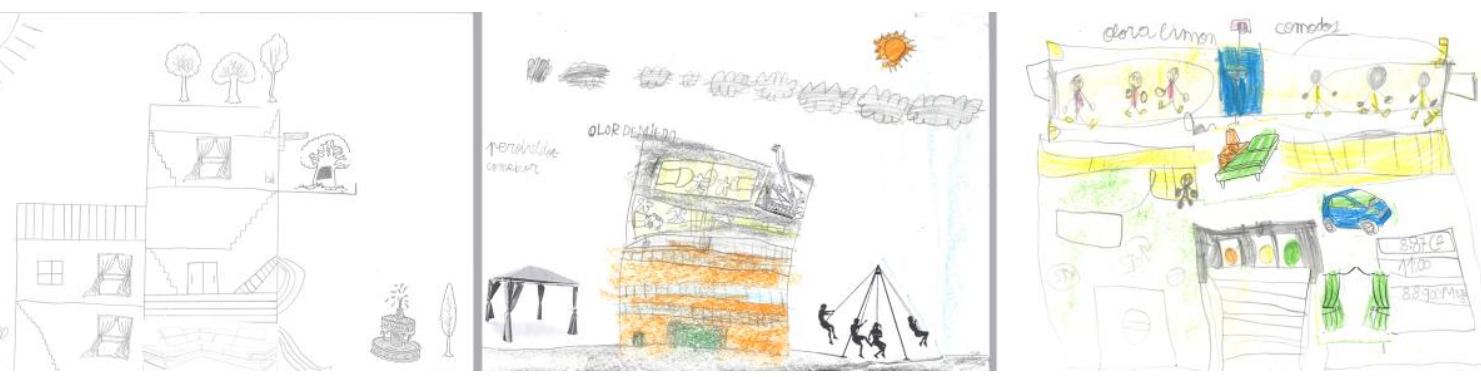

Fuente: elaborada a partir de los dibujos de Josué, Anís de $2^{\circ}$ y Cheto de $1^{\circ}$ del CEIP José Carlos Aguilera, 2016.

Sin embargo, hay quienes ingenian alternativas poco comunes. Son muy valoradas las cubiertas ajardinadas 0 transitables con un uso lúdico o de descanso (José_4﹎_CF), (Aitor_2o_JCA), (Josué_2o_JCA), (Luna_2o_JCA), (Anís_1﹎JCA), (Cheto_1﹎JCA), (Christian_1ํJCA), (Oscar_1ํ_JCA), (Paula_1ํ_JCA), (Sergio_1ํJCA), (Andrew_3o_JCA), (Aurora_1﹎.MLS), (Manuel_1﹎MLS), (Miriam, 4﹎MLS) [ver figura 3]. Las tres escuelas poseen cubiertas inclinadas o azoteas no transitables. Particularmente, el CEIP José Carlos Aguilera cuenta con una pequeña azotea sobre el comedor que fue ampliación del centro. Destaca, especialmente, el número de respuestas tan abundante del grupo de estudiantes del JCA (tanto del aula de 1을 que tiene una puerta que da acceso a dicha azotea no transitable, como de estudiantes de cursos superiores que también ocuparon esa clase) quienes reclaman el aprovechamiento de los tejados.

Figura 8 Serie muestra "fútbol"

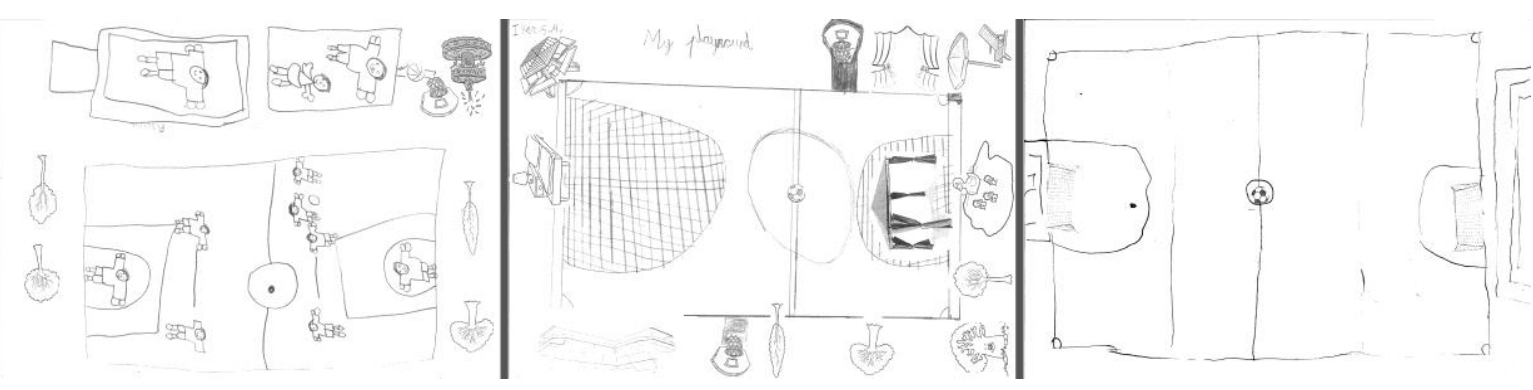

Fuente: elaborada a partir de los dibujos de Abraham de $1^{\circ}$ e lker de $4^{\circ}$ del CEIP Cañada del Fenollar, y Pedro de 4ํ del CEIP Maestro López Soria, 2016. 
La problemática para estos colegios es, por un lado, la falta de trasteros o sistemas de almacenamiento seguros en el patio que faciliten el reparto y por otro lado la recogida de materiales de forma autónoma por parte de quienes los usan. Pero también las dimensiones tan reducidas de estos patios que quedan destinados casi en exclusividad a pista de fútbol y/o baloncesto, convirtiéndose estos deportes en focos dominantes de la actividad recreativa con la subsecuente afección a quienes no comparten estas inquietudes y ven mermadas sus posibilidades de experimentación y juego. En gran parte de las representaciones de quienes ostentan más edad, los patios de fútbol centralizan todo el interés del área de recreo

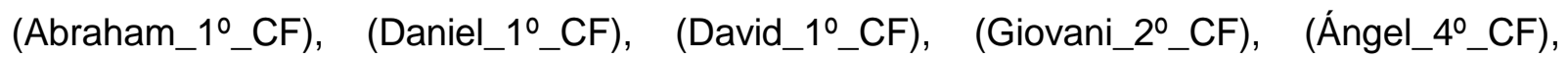

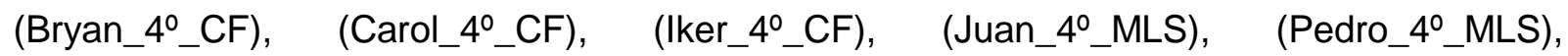

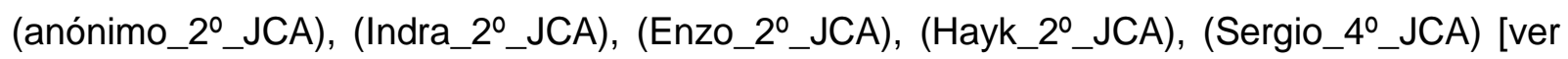
figura 6]. Debemos ser conscientes de las consecuencias de género implícitas que este reparto poco equitativo comporta, pues estos deportes son practicados mayoritariamente por niños (solo varones son los que han proyectado los patios de este modo), quienes desarrollan roles de poder derivados de la gestión del espacio y aprenden a imponer sus preferencias sobre las de las niñas. Las niñas de entre 6 y 9 años se mantienen así en la periferia del campo, en los márgenes o en la marginalidad (Noa_3﹎F) y reclaman la

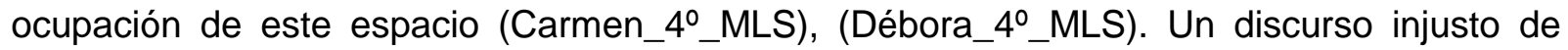
discriminación por razón de género que subyace en los patios de escuelas. Estos resultados coinciden con los destacados por Miranda, et al. (2015):

El espacio de gran parte de los patios analizados lo ocupaban las canchas de fútbol y de baloncesto. Además, en muchos de ellos las actividades deportivas eran las únicas propuestas disponibles, sin ninguna otra práctica alternativa. En muchos casos, pudimos observar a un gran grupo de niños, en su mayoría de sexo masculino, jugando al fútbol, ocupando la mayor parte del patio y relegando al resto de niños y niñas a espacios menos acogedores y con escasos recursos disponibles para participar en juegos alternativos. (p. 162)

Urge repensar pedagógicamente los patios de recreo para evitar la perpetuación de roles de género, los cuales obligan a las niñas a socializarse en lugares pequeños y a aceptar la jerarquización, mientras que prepara a los niños para competir y ocupar los lugares visibles y públicos. Pues como denuncian Rodríguez Navarro y García Monge (2009): 
Esta situación remarca valores como la competitividad en los niños, la licitud de que utilicen los mejores espacios, o el refuerzo de su competencia motriz. Las niñas, sin embargo, van asumiendo su papel secundario y van entrando en la inactividad o en la práctica de actividades menos complejas. (en cuanto a normativa y a dificultad motriz) (p. 66)

EI CEIP José Carlos Aguilera cuenta con un patio de recreo ampliado que supera en dimensiones al de las otras dos escuelas, pero no goza de ninguna zona parcialmente cubierta que garantice la sombra en una ciudad con tantas horas de sol como Alicante. El CEIP Cañada del Fenollar posee zonas arboladas que ofrecen sombra fresca, sin embargo se escuchan quejas respecto a los gusanos de procesionaria que invaden la especie mayoritariamente presente, los pinos. Esta problemática respecto a las zonas verdes es vista, por el colectivo mayor, desde dos perspectivas: manifiesta el deseo de crear un área de refresco, convierte en playa, o piscina el patio de recreo (Ainara_3ํCF), (Ainhoa_3늑),

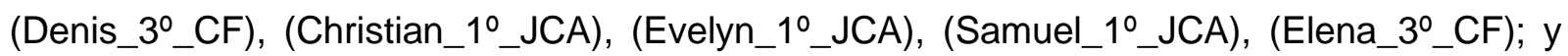
también desde una mirada más reivindicativa (Adam_3ㄴ_JCA) deja claro que el sol está bien pero que necesitan el fresco, y para ello introducen árboles, toldos y marquesinas.

Figura 9 Serie muestra "escuela de ladrillos"

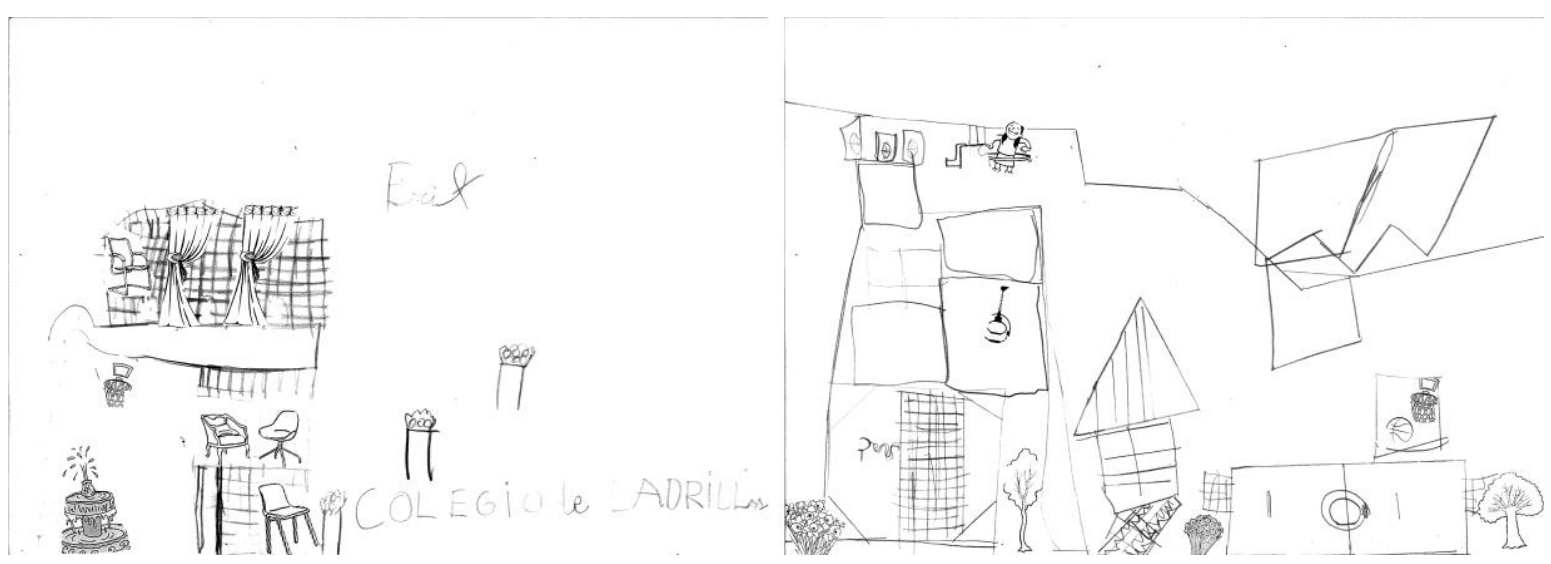

Fuente: elaborada a partir de los dibujos de Mireia de $1^{\circ}$ y Erik de 2 del CEIP Cañada del Fenollar, 2016.

Entre las necesidades específicas destacamos las del CEIP Cañada del Fenollar que padece las molestias de unas aulas que son realmente barracones o casetas prefabricadas de obra. El grupo de estudiantes mayor (segundo septenio), consciente de las afecciones 
derivadas de estas instalaciones provisionales, reclaman edificios de ladrillo (Cloes_1﹎_CF),

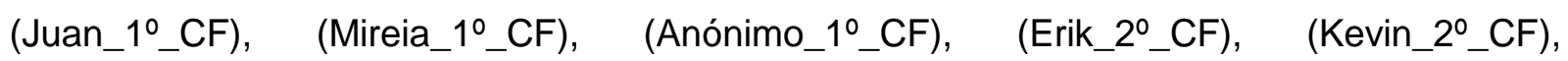

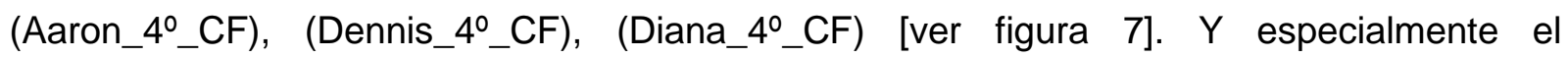
estudiantado de $4^{\circ}$ curso distribuye los espacios para dotarlos de todos los servicios: dirección, conserjería, biblioteca, informática, aseos e incluso enfermería (José_4ํCF), (Luna_4으C. $)$.

El entorno escolar diseñado fue libremente escogido por cada estudiante. Sin embargo, en la mayoría de los casos los y las estudiantes han optado por diseñar el patio que les gustaría tener o el colegio en su conjunto más que el aula o la edificación escolar. Esto puede ser interpretado de dos modos: o bien, el colectivo estudiantil entiende que las clases deben ser objeto de preocupación del cuerpo docente (mientras que sus competencias se corresponden con otros lugares de la escuela); o bien, considera que el espacio áulico ya está suficientemente concebido y deja poco margen de creatividad (Mariola_5inf_CF).

En algunos casos, en edades entre 7 y 9 años, incluso el participante quiere dejar claro que si no ha dibujado algún elemento es por deseo expreso, y lo refuerza mediante lenguaje escrito (Juan_1ํ_JCA), (Raúl_1﹎.JCA) como si al no incluirlo en su representación lograra su desaparición; esto ocurre, por ejemplo, con el comedor cuando es detestado. O utiliza el lenguaje escrito para matizar algún aspecto, por ejemplo el deseo de que el comedor se instale al aire libre (Aitor_4으두).

\subsection{Análisis cuantitativo}

El análisis de datos de forma cuantitativa se destina a aquellas repuestas cerradas que se dan al emplear las pegatinas prediseñadas para los y las estudiantes. Se calcula el número de veces que se ha adherido cada elemento según cursos y escuelas; y se divide entre el número de estudiantes participantes, esto para tener valores relativos que permitan la comparación posterior entre centros.

El análisis cuantitativo de las respuestas cerradas nos permite también comparar qué categorías temáticas tienen mayor presencia que otras para el estudiantado. El cálculo se realiza dividiendo el número total de veces que es utilizada una pegatina de esa categoría entre el número de pegatinas diferentes que conforman dicha categoría. (ver tabla 3). 
Figura 10 Hallazgos totales de cada pegatina

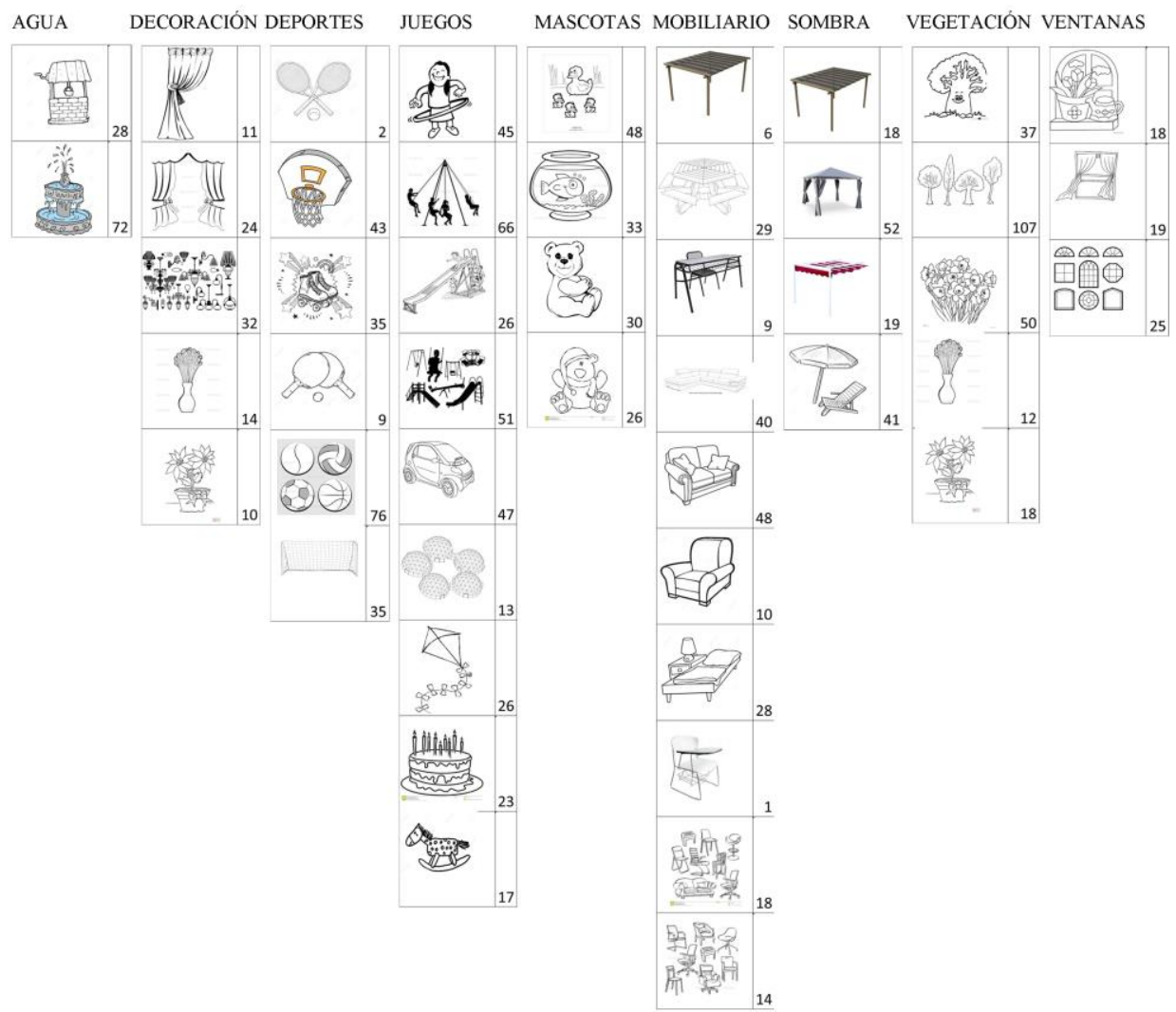

Fuente: elaboración propia a partir la información recolectada en la investigación, mediante el recuento de cada una de las pegatinas adheridas en los trabajos artísticos (como si fueran respuestas cerradas) y su agrupación en columnas según categorías temáticas, 2016.

Los elementos predominantes para ser incorporados en los dibujos por los y las discentes, son de mayor a menor presencia: árboles de gran porte (107), pelotas (76), fuentes (72), el columpio grupal (66), la jaima (52), los sofás (48 y 40) y el estanque de patos (48). 
Tabla 3. Hallazgos relativos a cada categoría temática presente en los trabajos infantiles de los colegios CEIP Cañada del Fenollar, CEIP José Carlos Aguilera, CEIP Maestro López Soria de Alicante, España entre los meses de octubre de 2015 y mayo de 2016.

\begin{tabular}{|c|c|c|c|c|c|c|}
\hline \multirow[b]{2}{*}{ CATEGORÍA } & \multicolumn{4}{|c|}{$\begin{array}{l}\text { HALLAZGOS DE } \\
\text { PEGATINAS EN LOS } \\
\text { TRABAJOS INFANTILES }\end{array}$} & \multirow{2}{*}{$\begin{array}{l}\text { ELEMENTOS } \\
\text { CATEGORÍA } \\
\text { № TIPO DE } \\
\text { PEGATINAS } \\
\text { DIFERENTES } \\
\text { EN } \\
\text { CATEGORÍA } \\
\end{array}$} & \multirow{2}{*}{$\begin{array}{l}\text { HALLAZGOS } \\
\text { RELATIVOS } \\
\\
\text { HALLAZGOS } \\
\text { TOTALES/ELEMENTOS } \\
\text { CATEGORÍA } \\
\end{array}$} \\
\hline & CF & JCA & MLS & $\begin{array}{l}\text { TOTALES } 3 \\
\text { COLEGIOS } \\
\end{array}$ & & \\
\hline AGUA & 32 & 40 & 28 & 100 & 2 & 50 \\
\hline VEGETACIÓN & 91 & 81 & 52 & 224 & 5 & 44,8 \\
\hline JUEGOS & 98 & 127 & 89 & 314 & 9 & 34,9 \\
\hline MACOTAS & 39 & 55 & 43 & 137 & 4 & 34,3 \\
\hline DEPORTEES & 70 & 60 & 70 & 200 & 6 & 33,3 \\
\hline SOMBRA & 42 & 46 & 42 & 130 & 4 & 32,5 \\
\hline VENTANAS & 19 & 27 & 16 & 62 & 3 & 20,7 \\
\hline MOBILIARIO & 61 & 67 & 75 & 203 & 10 & 20,3 \\
\hline DECORACIÓN & 41 & 24 & 26 & 91 & 5 & 18,2 \\
\hline $\begin{array}{l}\text { TOTAL } \\
\text { CATEGORÍAS }\end{array}$ & 452 & 503 & 415 & 1461 & 48 & 30,4 \\
\hline
\end{tabular}

Fuente: elaboración propia a partir de los datos recolectados en la investigación, mediante el recuento en cada trabajo artístico de dibujos identificables en las diferentes categorías, 2016.

Esto nos permite observar que el grupo de estudiantes, para un mayor confort en la escuela, prioriza las necesidades de agua relacionadas con la hidratación y también con la naturaleza; así como la vegetación, ya sean árboles o flores, que reportan sombra, belleza, buenos olores y cobijo a aves (y sus trinos). Parece una respuesta lógica de rechazo a sus patios asfaltados, pues según Miranda, et al. (2015) estos tipos distan "mucho de ser considerados como espacios naturales de aprendizaje" (p. 162). En la línea de centros que sí saben dar respuesta a estas demandas hallamos la Escuela Infantil Platero (2006) que ofrece un entorno natural de más de cien especies de plantas autóctonas y un huerto (como algunas otras escuelas) vinculado a un fabuloso proyecto pedagógico.

A continuación, las preferencias de las y los estudiantes se centran en los juguetes, columpios y otros materiales lúdicos que les estimulan sensorialmente y divierten, así como mascotas o materiales deportivos. Los elementos de cobijo y sombra en los patios también son importantes y en menor medida otros, como las ventanas, el mobiliario o por último, los elementos decorativos. 
Algunas propuestas de respuesta cerrada, desde el planteamiento de la recolección de datos, se diseñaron pensando que serían descartadas; elementos como la cama, el sofá de 6 plazas, la cama, las lámparas típicas de vivienda o las cortinas, entre otras. Inesperadamente el estudiantado sí ha optado por ellos, lo cual demuestra que desean un espacio estéticamente tan acogedor como un hogar: cálido, confortable y proclive al descanso también.

Entre las respuestas cerradas existen algunas alternativas, conceptualmente, muy similares entre sí pero diferentes en cuanto a estética; por ejemplo, variedad de sillas, de lámparas o de sillones; y otras que forman parte de un compendio de elementos agrupados dentro de la misma familia; por ejemplo, lámparas, sillas, columpios y pelotas. Quienes participan de este estudio demuestran tener criterio estético al decantarse con mayor frecuencia por unos adhesivos (dibujos) antes que por otros. Lo demuestran por ejemplo, al seleccionarlos y recortarlos de entre los semejantes, o buscar duplicados en hojas adhesivas de sus pares, aun cuando la funcionalidad es similar con otras pegatinas.

\section{Discusión}

De la interpretación de los resultados cualitativos y cuantitativos obtenidos podemos extraer que existe un criterio infantil subyacente discernible. Este criterio se manifiesta en la capacidad de organizar el espacio conforme a unidades temáticas o funcionales (solo en dos casos muy puntuales, del conjunto de la muestra, parece que se sitúan los elementos arbitrariamente). De manera que se agrupan elementos como la fuente, el pozo, el estanque de patos, las aguas termales, el jacuzzi o la piscina conformando una zona húmeda (Oriol_5inf_CF), (Andrew_3﹎.JCA); diversos tipos de sillas, sillones y sofás creando un área

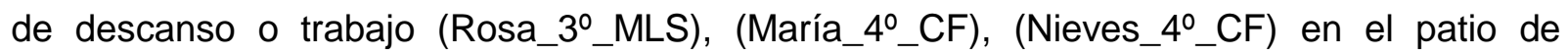
primaria; flores, plantas y árboles creando alineamientos vegetales; porterías y pelotas en un campo de fútbol o canastas con sus respectivos balones en un campo de baloncesto... También puede reconocerse el criterio estético en aquellas propuestas imposibles planteadas por estudiantes de primaria con una mayor madurez intelectual que, aun siendo conscientes de las limitaciones reales, deciden fantasear para convertir su escuela en un lugar más creativo, mágico y especial, con elementos voladores, apariencia de castillo y mobiliario con formas orgánicas... (Yerai_3﹎_CF), (Sarai_4ㄴ_CF), (Aida_3ㅇ﹎CA), (Gonzalo_3﹎JCA), (Albert_3﹎JCA), (Rafael_4inf_MLS), (José_2ํMLS). En otro caso, el criterio estético es próximo a las influencias de la cultura visual, y se vislumbran estéticas 
violentas de los videojuegos (Enzo_3﹎F), (Gabriel_3﹎F), (Álvaro_4ํCF), (Izan G_3ㅇJCA), (Nicolás_3﹎.JCA), (Omar_3ㄴJCA) a partir de los 7 años como sugieren los estudios de Ives y Gardner (1984). Incluso, se observa que el grupo de estudiantes, sensible a los estímulos multisensoriales, incluye, en sus propuestas, matices estéticos relacionados con todos los sentidos: la música a través de altavoces en el patio, el trinar de los pájaros, el olor de frutas o de las múltiples flores tan presentes en los dibujos, los colores de las superficies (Daniela_4inf_CF).

\section{Conclusiones}

Existe un criterio estético infantil conformado entre escolares. Se demuestra la necesidad de tomar en cuenta al estudiantado en los procesos de diseño pedagógicoarquitectónico y se constata que las infraestructuras actuales no responden a las necesidades ni deseos del cuerpo estudiantil. La sensibilidad infantil hacia ciertas estéticas como las deportivas, naturales, lúdicas o fantásticas va a depender, en gran medida, del grado de conocimiento previo que se tenga de dichos estímulos. Por ende, las experiencias satisfactorias generadas por estímulos gratificantes generan el deseo de seguir manteniendo los elementos que las provocan, tales como columpios y juguetes estimulantes en los patios. Y por el contrario, si habitualmente no están estimulados por un determinado tipo de elementos, o son desconocedores de la experiencia que supone convivir con ellos, sus postulaciones van a disminuir, así como su capacidad de gozo y experiencia estética.

Los elementos ausentes (en número, tamaño y tipología) que serían necesarios para un mayor confort y calidad educativa, desde el punto de vista discente son, en el patio: [1] recursos hídricos como fuentes y piscinas, zonas de sombra como marquesinas y jaimas, o arboledas para lograr ambientes frescos; [2] zonas naturales con árboles de gran porte, vegetación floral o huertos, y también animales domésticos; [3] columpios, juguetes y materiales deportivos que les estimulen sensorialmente; [4] zonas de descanso o áreas de recogimiento; [5] diversas pistas deportivas y artísticas; [6] elementos coloridos y atractivos como murales lúdicos en el suelo. $Y$ en las aulas: [1] pizarras digitales, ordenadores o videojuegos; [2] ventanas para una buena iluminación natural y vistas a los patios; [3] mobiliario de descanso y decoración hogareña; [4] mascotas.

Los elementos presentes en el entorno educativo que sería preciso eliminar o modificar para un mayor confort y calidad educativa, desde el punto de vista discente son: [1] vallas o divisiones entre áreas; [2] libros de texto $u$ otros materiales didácticos tradicionales. Y los 
elementos existentes que se mantienen son: [1] columpios característicos de su colegio con carga identitaria y toboganes; [2] pistas de fútbol y baloncesto; [3] vegetación; [4] amigos.

La estética de los entornos educativos deseados queda definida como espacios frescos, naturales, concebidos tanto para la actividad lúdica o el aprendizaje como para el descanso y las relaciones interpersonales afectivas. Espacios atractivos, acogedores, cómodos y hogareños, permeables al entorno exterior y con apariencia externa original.

\section{Agradecimientos}

Se agradece a las comunidades educativas de los colegios de educación infantil y primaria Cañada del Fenollar, José Carlos Aguilera y Maestro López Soria su participación en esta investigación, especialmente al colectivo escolar por su implicación.

\section{Referencias}

Armstrong, Thomas. (2006). Inteligencias múltiples en el aula (Ed. orig. 2000). Barcelona: Paidós Educador.

Aguirre, Imanol. (2005). Teorías y prácticas en Educación Artística. Barcelona: Octaedro.

Alschuler, Rose H. y Hattwick, La Berta Weiss. (1947). Painting and Personality. A Study of Young Children. Chicago: University of Chicago Press.

Araneda, Claudio. (2010). Protofenómeno Arquitectónico: introduciendo la noción de fenómeno primordial en arquitectura. Arquitetura Revista, 6(2), 76-89. Recuperado de http://revistas.unisinos.br/index.php/arquitetura/article/view/4550

Auge, Marc. (2000). Los "no lugares" espacios del anonimato. Una antropología de la Sobremodernidad. Barcelona: Gedisa.

Bezerra Barbosa, Fátima María y Pino-Juste, Margarita. (2011). A estética como factor promotor da aprendizagem. Teoría educativa, 23(2), 91-109.

Burke, Catherine. (2007). The View of the Child: Releasing "visual voices" in the design of learning environments. Discourse: studies in the cultural politics of education, 28(3), 359-372. doi: http://dx.doi.org/10.1080/01596300701458947

Burke, Catherine, Gallagher, Claire Prosser, Jon, y Torrington, Judy. (2006). The view of the child: Explorations of the visual culture of the made environment. En Economic and Social Science Research Council (ESRC) Conference on Pupil Voice, Nottingham, UK.

Burke, Catherine y Grosvenor, Ian (Eds.). (2003). The School l'd Like. Children and Young People's Reflections on an Education for the $21^{\text {st }}$ Century. New York: RoutledgeFalmer. 
Cabezas, Hannia y Monge, Melania. (2014). Influencia del entorno donde se ubica el centro educativo en la presencia del acoso en el aula. Actualidades investigativas en Educación, 14(3), 1-22.

Campo, Benito; Císcar Josep, y Souto, Xosé Manuel. (2014). Los espacios de la periferia escolar. Scripta Nova, 496(18), 1-19.

Cantó Alcaraz, Ramón y Ruiz Pérez, Luís Miguel. (2005). Comportamiento Motor Espontáneo en el Patio de Recreo Escolar: Análisis de las diferencias por género en la ocupación del espacio durante el recreo escolar. International Journal of Sport Science, 1, 28-45. doi:10.5232/ricyde2005.00103.

Clark, Alison. (2010). Young children as protagonists and the role of participatory, visual methods in engaging multiple perspectives. American Journal of Community Psychology, 46(1), 115-123. doi:10.1007/s10464-010-9332-y

Errázuriz-Larraín, Luis Hernán. (2014). Cultura visual escolar: Investigación de los muros de primero básico. Estudios Pedagógicos, 40(2), 135-146.

Errázuriz-Larraín, Luis Hernán. (2015). Calidad estética del entorno escolar: el (f)actor invisible. Arte, Individuo y Sociedad, 27(1), 81-100. http://dx.doi.org/10.5209/rev ARIS.2015.v27.n1.43861

Equip de l'Escola Bressol Municipal Els Belluguets. (2010). Descobrim noves possibilitats d'un Iloc poc reconegut: el pati de l'escola. Guix d'Infantil, (58), 15-17.

Equipo educativo EEI Platero. (2006). El pati de l'escola: un bosc ple de vida. Guix d'Infantil, (33), 26-30.

Fisher, Kenn. (2005). Linking pedagogy and space. Melborune, Victoria, Australia: Department of Education and Training.

Flores, Luis Manuel. (2015). La cuestión del clima y el espacio escolar: lineamientos y proyecciones pedagógicas. En Luis Hernán Errázuriz-Larraín (Ed.), El (f)actor invisible. Estética cotidiana y cultura visual en espacios (pp. 101-109). Santiago de Chile: Consejo Nacional de la Cultura y las Artes.

Gairín Sallán, Joaquín. (1995). El reto de la organización de los espacios. Revista Aula de Innovación Educativa, (39). Recuperado de http://aula.grao.com/revistas/aula/39crecer-en-literatura--la-organizacion-del-espacio/el-reto-de-la-organizacion-de-los$\underline{\text { espacios }}$

Gallart, Neus. (2008). El nostre pati: un paisatge escolar. Guix, (346-347), 39-44.

Hernández-Hernández, Fernando. (2010). Educación y cultura visual (Ed. orig. 1997). Barcelona: Ediciones Octaedro.

Huerta, Ricard. (2015). Lo que se ve y lo que no se ve. Una mirada a los muros de salas de primero básico de algunos colegios chilenos. En Luis Hernán Errázuriz-Larraín (Ed.), El 
(f)actor invisible. Estética cotidiana y cultura visual en espacios escolares (pp. 131155). Santiago de Chile: Consejo Nacional de la Cultura y las Artes.

Ives, S. William y Gardner, Howard. (1984). Cultural influences on children's drawings: A developmental perspective. En Robert Ott y Al Hurwitz (Eds.), Art in Education: An international perspective (pp. 13-30). Pennsylvania State: University Press.

Johnson, David W. y Johnson, Roger T. (1975). Learning together and alone, cooperation, competition and individualitation. Englewood Cliffs, Nueva Jersey: Prentice Hall.

Jonassen, David. H. (1994). Thinking technology: Toward a constructivist design model. Educational Technology, 34(4), 34-37.

Light, Andrew y Smith, Jonathan M. (2005). The Aesthetic of Everyday Life. Columbia: University Press.

Lipponen, Lasse, Rajala, Antti, Hilppö, Jaakko, y Paananen, Maiju. (2016). Exploring the foundations of visual methods used in research with children. European Early Childhood Education Research Journal, 24(6), 936-946. http://dx.doi.org/10.1080/1350293X.2015.1062663

Mandoki, Katya. (1994). Prosaica, Introducción a la Estética de lo Cotidiano. México: Editorial Grijalbo.

Mandoki, Katya. (2006). Estética Cotidiana y Juegos de la Cultura. México: Siglo XXI Editores.

Marín, Inma. (2012). Els patis de les escoles: espais d'oportunitats educatives. Guix, (389), 33-35.

Marín, Ricardo. (2005). La "Investigación Educativa Basada en las Artes Visuales" o "Arteinvestigación educativa". En Ricardo Marín (Ed.), Investigación en Educación Artística: temas, métodos y técnicas de indagación sobre el aprendizaje y la enseñanza de las artes y culturas visuales (pp. 223-274). Granada: Editorial Universidad de Granada.

Marín, Ricardo y Roldán, Joaquín. (2008). Imágenes de las miradas en el museo. Un fotoensayo descriptivo-interpretativo a partir de Honoré Daumier. En Román de la Calle y Ricard Huerta (Eds.), Mentes Sensibles. Investigar en Educación y Museos (pp. 97108). València: Publicacions de la Universitat de Valencia.

Marín, Ricardo y Roldán, Joaquín. (2009). Proyecciones, tatuajes y otras intervenciones en las obras del museo (Un fotoensayo a partir de T. Struth). Arte, Individuo y Sociedad, (21), 99-106.

Marín, Ricardo y Roldán, Joaquín. (2010). Photo essays and photographs in visual artsbased educational research. International Journal of Education through Art, 6(1), 7-23.

Miranda, Nekane, Larrea, Iñaki y Muela, Alexander. (2014). Ikastetxeetako kanpo espazioen kalitatea Haur Hezkuntzan. Tantak, 26(2), 59-76. 
Miranda, Nekane, Larrea, Iñaki, Muela, Alexander, Martínez de Lagos, Aitziber y Barandiaran, Alexander. (2015). Mejora del espacio exterior escolar desde la participación comunitaria. Participación educativa Segunda Época, 4(7), 161-168.

Molina, Marta, Castro, Encarnación, Molina, José Luis y Castro, Enrique. (2011). Un acercamiento a la investigación de diseño a través de los experimentos de enseñanza. Enseñanza de las Ciencias, 29(1), 75-88.

Naranjo, Gabriela. (2011). La construcción social y local del espacio áulico en un grupo de escuela primaria. CPU-e, Revista de investigación Educativa, 12, 1-27. Recuperado de https://www.uv.mx/cpue/num12/inves/naranjo-construccion-social.html

Pérez, Paula y Córdoba, Ana Isabel. (2015). El aula creativa como propuesta pedagógica de desarrollo integral desde la infancia. Creatividad y Sociedad, 23, 128-160. Recuperado de

http://www.creatividadysociedad.com/articulos/23/5 El\%20aula\%20creativa\%20como\% 20propuesta\%20pedagogica\%20de\%20desarrollo\%20integral\%20desde\%20la\%20infa ncia.pdf

Rinaudo, María Cristina y Donolo, Danilo. (2010). Estudios de diseño. Una perspectiva promisoria en la investigación educativa Revista de Educación a Distancia, 22, 1-29. Recuperado de http://www.um.es/ead/red/22/

Rodríguez Navarro, Henar y García Monge, Alfonso. (2009). Asimilación de códigos de género en las actividades del recreo escolar. Revista Interuniversitaria de Formación del Profesorado, 23(1), 59-72.

Rota, Angi. (2014). Un pati d'un nombre infinit de colors. Guix, (406-407), 62.

Saito, Yuriko. (2007). Everyday Aesthetic. Oxford, Reino Unido: Oxford University Press. 